\title{
Effects of pegbovigrastim administration on periparturient diseases, milk production, and reproductive performance of Holstein cows
}

\author{
M. Zinicola, H. Korzec, A. G. V. Teixeira, E. K. Ganda, L. Bringhenti, A. C. C. H. Tomazi, R. O. Gilbert, \\ and R. C. Bicalho ${ }^{1}$ \\ Department of Population Medicine and Diagnostic Sciences, Cornell University, Ithaca, NY 14853-6401
}

\begin{abstract}
The aim of this study was to evaluate the effects of treating Holstein cows with pegbovigrastim on periparturient diseases, milk production, and reproductive performance while exploring the mode of action of an immunomodulatory protein. Cows were randomly allocated to 1 of 2 treatments, untreated control (CTR, $\mathrm{n}=423)$ and pegbovigrastim $(\mathrm{PEG}, \mathrm{n}=417)$. At 7 $\mathrm{d}$ from the anticipated calving date $(\mathrm{d}-7)$, cows allocated to PEG received a subcutaneous injection of $15 \mathrm{mg}$ of pegylated recombinant bovine granulocyte colony stimulating factor (pegbovigrastim injection, Imrestor, Elanco Animal Health, Greenfield, IN). A second injection was administered within $24 \mathrm{~h}$ after calving (d 0). Blood samples were obtained from a subset of cows (CTR, $\mathrm{n}=103$; PEG, $\mathrm{n}=102$ ) at -7 and $0,3,7$, and $14 \mathrm{~d}$ relative to parturition. Samples were used for hemogram and quantification of haptoglobin, nonesterified fatty acids, $\beta$-hydroxybutyrate, and trace and macro minerals. Vaginal cytobrush was performed on the same subset cows at d 0,7 , and 14 to assess the relative neutrophil count. Additionally, colostrum samples were collected to measure $\operatorname{Ig} \mathrm{G}, \operatorname{IgM}, \operatorname{IgA}$, and lactoferrin concentrations. Postpartum disease occurrence was recorded from calving until $30 \mathrm{~d}$ in milk (DIM). Weekly milk yield was recorded for the first 12 wk after calving. Cows treated with PEG had a 3- to 4 -fold increase in circulating polymorphonuclear leukocyte, lymphocyte, and monocyte numbers, with a peak at $3 \mathrm{~d}$ after treatment followed by a gradual decline, but the counts remained significantly greater compared with CTR at 14 DIM. The administration of PEG did not affect the incidence of clinical and subclinical mastitis, retained fetal membranes, metritis, puerperal metritis, and endometritis. Primiparous cows treated with PEG tended to have lower odds of developing hyperketonemia than CTR [odds ratio $(\mathrm{OR})=0.57$,
\end{abstract}

Received April 3, 2018.

Accepted August 30, 2018.

${ }^{1}$ Corresponding author: rcb28@cornell.edu
95\% confidence interval $(\mathrm{CI})=0.23$ to 1.42$]$. Cows treated with PEG had higher odds of being diagnosed with lameness within 30 DIM compared with CTR (OR $=1.79,95 \% \mathrm{CI}=1.16$ to 2.76 ); however, we found no significant differences by 60 DIM. Treatment with PEG increased the odds of displaced abomasum $(\mathrm{OR}=$ $8.27,95 \% \mathrm{CI}=1.02$ to 66.6 ). Cows treated with PEG had higher odds of being diagnosed with 1 or more clinical diseases compared with CTR cows $(\mathrm{OR}=1.39$, $95 \% \mathrm{CI}=1.02$ to 1.90$)$. We observed no differences in linear scores or milk composition between treatments. Furthermore, primiparous cows treated with PEG produced more milk than CTR primiparous cows during the first 12 wk postpartum $(\mathrm{PEG}=37.51 \pm 0.66$; CTR $=35.91 \pm 0.65 \mathrm{~kg}$ ), but no differences were observed on energy-corrected milk. Treatment did not alter reproductive performance; additionally, cows diagnosed with metritis or puerperal metritis and treated with PEG tended to have higher proportion of neutrophils in the vaginal mucosa when compared with CTR metritic cows. Although PEG treatment increased circulating polymorphonuclear leukocyte, monocyte, and lymphocyte numbers, as expected, it was detrimental to cow health because it increased morbidity.

Key words: Holstein, mastitis, metritis, pegbovigrastim

\section{INTRODUCTION}

During the early postpartum period, dairy cows can experience several infectious and metabolic disorders (Seegers et al., 2003; Duffield et al., 2009; Dubuc et al., 2010) that are costly to the producer and compromise the welfare of the animals (Fetrow et al., 2000; Dubuc et al., 2011). Despite decades of research dedicated to advancing knowledge and aiding in the prevention of periparturient disorders (e.g., mastitis, retained placenta, and metritis) their incidence still considerably high (Ribeiro et al., 2013). Thus, novel treatment options and control programs are required for dairy cattle.

Mastitis is highly prevalent in dairy cows and arguably the most important disease for the dairy industry worldwide (Seegers et al., 2003; Gröhn et al., 
2004; Cha et al., 2011). Treatment and prevention of mastitis have been reported to be the principal reason for antibiotic usage in dairy farms, accounting for $80 \%$ of the antimicrobial dugs used in the dairy industry (Pol and Ruegg, 2007). Intensive use of antimicrobials provides opportunity for antimicrobial resistance to develop in mastitis pathogens (Oliver and Murinda, 2012) and increases the risk of residue violation (Ruegg and Tabone, 2000). Therefore, efforts have been made to manage mastitis and prevent the indiscriminate use of antibiotics in dairy farms (Schreiner and Ruegg, 2003; Landin et al., 2015; Ganda et al., 2016).

Neutrophils are the main cell line of defense involved in bacterial clearance after uterine (Hussain, 1989) and mammary gland (Paape et al., 2002) infection, and neutrophils play a major role in placental release (Kimura et al., 2002). However, impairment of neutrophil function during the peripartum period has been well documented and is a key contributing factor to the high incidence of postpartum infectious diseases (Kehrli et al., 1989; Kimura et al., 1999; Rinaldi et al., 2008). Indeed, postpartum uterine diseases and mastitis have been associated with decreased neutrophil function (Waller, 2000; Kimura et al., 2002; Hammon et al., 2006). Additionally, it has been shown that greater influx of neutrophils into the uterus during the early postpartum period is associated with improved uterine health and reproductive performance (Gilbert and Santos, 2016).

Granulocyte colony stimulating factor (G-CSF) is an endogenous hematopoietic growth factor that stimulates the production and differentiation of neutrophils by progenitor cells in the bone morrow (Nagata, 1989). In humans, the prophylactic use of G-CSF has been demonstrated to be effective in reducing the incidence of febrile neutropenia, a frequent event observed in cancer patients treated with chemotherapy and characterized by neutrophil numbers below normal values (Cooper et al., 2011).

Recently, a commercially available recombinant bovine G-CSF (pegbovigrastim, Imrestor, Elanco Animal Health, Greenfield, IN) was shown to increase the concentrations of circulating neutrophils and enhanced in vitro myeloperoxidase (MPO) release from neutrophils of periparturient cows (McDougall et al., 2017). However, in that study, neutrophil phagocytic activity, oxidative burst, and MPO function did not differ between treated and untreated cows (McDougall et al., 2017); similar results were observed in a previous study (Kimura et al., 2014).

Recent studies have evaluated the effect of pegbovigrastim administration with the objective of reducing the occurrence of clinical mastitis (CM) in postpartum
Holstein cows (Hassfurther et al., 2015; Canning et al., 2017; Ruiz et al., 2017). In a study conducted by Hassfurther et al. (2015), cows treated with pegbovigrastim at 10 and $20 \mu \mathrm{g} / \mathrm{kg}$ experienced significantly fewer cases of CM (9/54 and 5/53, respectively) compared with control cows (18/53). Canning et al. (2017) evaluated the effect of pegbovigrastim on postpartum CM incidence from 4 dairy farms located in different states of the United States and observed that treated cows had a 35\% reduction of CM incidence overall (across all dairies) compared with controls. Moreover, a reduction in CM incidence of $25 \%$ was reported in cows treated with pegbovigrastim relative to controls (Ruiz et al., 2017).

We hypothesized that administration of pegbovigrastim would increase neutrophil numbers in blood and we expected that treated cows would have a reduced incidence of postpartum disorders. Thus, the objectives of the present study were to evaluate the effect of pegbovigrastim administration on (1) circulating blood cells, (2) the incidence of mastitis (clinical and subclinical) and uterine diseases, and (3) production and reproductive performance. Moreover, serum metabolic markers [nonesterified fatty acids (NEFA) and BHB], plasma minerals, systemic inflammation (haptoglobin), and the concentrations of immunoglobulins and lactoferrin in colostrum were assessed.

\section{MATERIALS AND METHODS}

\section{Ethics Statement}

The research protocol was reviewed and approved by the Cornell University Institutional Animal Care and Use Committee (protocol number 2016-0028). The methods were carried out in accordance with the approved guidelines.

\section{Farm and Experimental Design}

The study was conducted in a large commercial dairy farm located near Ithaca, New York. The farm milked $\sim 3,800$ Holstein cows thrice daily in a rotary parlor with integrated milk meters that recorded individual production at every milking (DeLaval, Tumba, Sweden). The cows were housed in freestall barns with concrete stalls bedded with manure solids treated with quicklime $(\mathrm{CaO})$. The diet was formulated to meet or exceed the NRC nutrient requirements for lactating Holstein cows weighing $650 \mathrm{~kg}$ and producing $45 \mathrm{~kg}$ of $3.5 \%$ FCM. When a cow demonstrated signs of calving, it was moved to an individual maternity pen for delivery, where trained farm personnel assisted with 
parturition as needed, and then transferred to a postpartum pen after calving. Calves were removed from their dams immediately after birth. The farm reproductive management used for the first service a PresynchOvsynch protocol in combination with estrus detection and AI (Pursley et al., 1995; Moreira et al., 2001). After the first service, cows were submitted to the Resynch (Fricke et al., 2003) protocol and were allowed to be inseminated at detected estrus. A voluntary waiting period of $50 \mathrm{~d}$ was used. Estrus was detected based only on electronic activity sensors (Alpro, DeLaval) worn around the neck. Pregnancy was diagnosed on $\mathrm{d}$ $39 \pm 3$ after AI via rectal examination. Cows diagnosed as pregnant were reexamined $21 \mathrm{~d}$ later for detection of viable pregnancy on d $60 \pm 3$. Pregnant cows were considered as diagnosed pregnant at the first rectal examination. Pregnancy loss was defined as the absence of a viable pregnancy at the second rectal examination.

A randomized clinical trial design was used. In total, 885 primiparous and multiparous cows were enrolled in the study from September 2016 to December 2016. At enrollment, all cows were scored for BCS (Edmonson et al., 1989) and rectal temperature (RT) was recorded. To be enrolled in the study, cows had to meet inclusion criteria of: $\mathrm{BCS}>2.75$ and $<4$, nonlame, and $\mathrm{RT}<40.0^{\circ} \mathrm{C}$. Cows with a gestation length $>265 \mathrm{~d}$ were eligible to be enrolling in the study. Treatment allocation was done by parity in 2 separate randomization sheets on the day of the first pegbovigrastim injection. Multiparous cows were blocked by previous 305-d mature-equivalent lactation yields. Cows were then randomly allocated to 1 of 2 treatment groups: untreated control (CTR; $\mathrm{n}=423)$ and pegbovigrastim $(\mathbf{P E G} ; \mathrm{n}=417)$. At 7 $\mathrm{d}$ from the anticipated calving date, cows allocated to PEG received a subcutaneous injection containing 15 $\mathrm{mg}$ of pegylated recombinant bovine G-CSF in $2.7-\mathrm{mL}$ prefilled syringes (pegbovigrastim injection, Imrestor, Elanco Animal Health). A second injection was administered within $24 \mathrm{~h}$ after calving. Subjects that did not receive the first $(\mathrm{n}=10)$ or the second $(\mathrm{n}=35)$ dose of PEG were excluded from the study; therefore, 840 cows (primiparous, $\mathrm{n}=238$; multiparous, $\mathrm{n}=602$ ) were used. All treatments were performed by the researchers. To avoid biases, treatment identification was not listed in the data collection forms or in the on-farm herd management software Dairy Comp 305 (Valley Agricultural Software, Tulare, CA).

\section{Animal Sampling}

Blood samples were drawn into $10-\mathrm{mL}$ vacutainer $\mathrm{K}_{2}$ EDTA blood collection tubes (BD Vacutainer, Franklin Lakes, NJ) from a subset of cows (PEG, $\mathrm{n}=102,37$ primiparous, 65 multiparous; CTR, $\mathrm{n}=103,39$ primiparous, 64 multiparous) from coccygeal vessels at $7 \mathrm{~d}$ before the expected calving date $(\mathrm{d}-7$; right before the first treatment injection), within $24 \mathrm{~h}$ after parturition (d 0 ; right before the second treatment injection), 3 DIM, $7 \pm 3$ DIM (d 7), and $14 \pm 3$ DIM (d 14). After collection, samples were immediately placed on ice. Samples were used for hemogram determination within $6 \mathrm{~h}$ of blood collection using a Vet hemogram instrument (Hematrue, Heska, Loveland, CO), and plasma was obtained by centrifugation at 2,000 $\times g$ for $15 \mathrm{~min}$ at $4^{\circ} \mathrm{C}$ and frozen at $-80^{\circ} \mathrm{C}$. Using the same subset of the study population, the relative neutrophil count of the reproductive tract was assessed in the vaginal mucosa from samples collected at d 0,7 , and $35 \pm 3$ DIM. Briefly, restrained cows had their perineum area cleaned and disinfected with $70 \%$ ethanol, and samples were collected by introducing a cytobrush into the vagina. Slides for cytological examination were prepared by rolling the cytobrush onto a clean-labeled glass microscope slide, air-dried immediately on farm, and stained at the laboratory. Each slide was exanimated at $400 \times$ magnification by a single observer. The observer counted a total of 200 cells from each slide at 2 to 4 different locations and the percentage of neutrophils among total cells was calculated. For each cow, RT and BCS were measured at the blood collection time points; BCS was also scored at d 35. Additionally, metritis and endometritis diagnosis was performed using a Metricheck device (Metricheck, SimcroTech, Hamilton, New Zealand) in all study cows on d 7 and 35, respectively.

Detection of subclinical mastitis (SCM) was performed by the researchers at $10 \pm 3$ DIM for all cows enrolled in the study using a California Mastitis Test (CMT) after milking; the results were recorded for each quarter of the udder. Furthermore, composited milk samples were collected from a subset of cows (primiparous: PEG, $\mathrm{n}=23$; CTR, $\mathrm{n}=22$; multiparous: PEG, $\mathrm{n}=87$; CTR, $\mathrm{n}=97$ ) at $7 \pm 3,14 \pm 3,21 \pm 3$, and $28 \pm 3$ DIM by the official Ithaca DHI for cow-level SCC analysis. In addition, DHI performed monthly visits to the farm and collected milk samples from all cows enrolled in the study to evaluate the monthly incidence of SCM. Linear somatic cells score was calculated as

$$
\mathrm{SCS}=\left[\ln \left(\mathrm{SCC} / 100 \times 10^{3}\right) / 0.693147\right]+3 .
$$

Last, a convenience sampling method was used to collect colostrum samples from 200 cows (100/treatment) to quantify $\operatorname{IgG}, \operatorname{IgA}, \operatorname{IgM}$, and lactoferrin concentrations. Briefly, teat ends were cleansed and $10 \mathrm{~mL}$ of colostrum from each quarter was sterilely collected into 50-mL Falcon tubes (VWR International, Radnor, 
PA), placed on ice and transported to the laboratory and frozen at $-20^{\circ} \mathrm{C}$. Colostrum samples were collected before blood collection on $\mathrm{d} 0$.

\section{Plasma and Colostrum Analysis}

Plasma concentrations of NEFA (NEFA-C kit; Wako Pure Chemical Industries, Richmond, VA) and BHB [kit \#310-UV, Sigma-Aldrich, St. Louis, MO (Williamson and Mellanby, 1974)] were determined by colorimetric methods. Haptoglobin concentrations were determined using a colorimetric procedure as previously described (Bicalho et al., 2014). The intra- and inter-assay coefficients of variation for the assays were $<8.5$ and $<10.5 \%$, respectively. Samples collected at d 0 from cows entering their third or greater lactation (PEG, $\mathrm{n}=33 ;$ CTR, $\mathrm{n}=30$ ) were sent to the Veterinary Diagnostic Laboratory at Iowa State University (Ames) for analysis of $\mathrm{Ca}, \mathrm{Cu}, \mathrm{Fe}, \mathrm{K}, \mathrm{Mg}, \mathrm{Mn}, \mathrm{P}$, Se, and $\mathrm{Zn}$. The concentrations of plasma minerals were analyzed using an inductively coupled plasma mass spectrometry system (Varian/Bruker 820 ICP-MS, Bruker Corporation, Fremont, CA) through separation of analyte ions from spectral interferences.

Enzyme-linked immunosorbent assays were used to quantify colostrum IgG (Immuno-Tek Bovine IgG ELISA Kit, ZeptoMetrix Corporation, Buffalo, NY), IgM, IgA, and lactoferrin (Bovine ELISA Kit, Bethyl Laboratories, Montgomery, TX) concentrations. Colostrum samples were thawed and homogenized, and aliquots of $1.5 \mathrm{~mL}$ were centrifuged at $10,000 \times g$ for $15 \mathrm{~min}$ at $4^{\circ} \mathrm{C}$, then the supernatant was collected for analysis. Serial dilution steps $(100 \times 100 \times 100)$ were performed to achieve a final total dilution of $1: 1,000,000$. The intra- and inter-assay coefficients of variation for the ELISA were $<7$ and $<9.5 \%$, respectively.

\section{Disease Definitions}

Stillbirth was defined as a dead calf at birth. Dystocia was defined as a calving that required assistance from farm personnel. Retained placenta (RP) was defined as cows that failed to release the fetal membranes within $24 \mathrm{~h}$ after calving (Kelton et al., 1998). Metritis diagnosis was performed by the researchers at $7 \pm 3 \mathrm{~d}$ using the Metricheck device and defined as the presence of fetid, watery, red-brown uterine discharge. Puerperal metritis diagnosis was performed by the researcher and by trained farm personnel. Researcher-diagnosed puerperal metritis was defined as cows having metritis with $\mathrm{RT}>39.5^{\circ} \mathrm{C}$ (Sheldon et al., 2006). On-farm diagnosis of puerperal metritis was performed daily by trained farm employees. Cows were flagged for a physical examination when showing signs of dullness and depression or when a milk deviation of more than $4.5 \mathrm{~kg}$ was detected. At the physical examination, cows were considered to have puerperal metritis when a fetid, watery, and red-brown uterine discharge combined with systemic illness was observed. For the purpose of our study, cows diagnosed with puerperal metritis by the research team or by farm employees were grouped together and considered positive for puerperal metritis. Furthermore, information regarding puerperal metritis diagnosis was not exchanged between the researchers and farm personnel. For some analyses, metritis and puerperal metritis were combined (metritis-PM). Fever was considered as cows having $\mathrm{RT}>39.5^{\circ} \mathrm{C}$ on $\mathrm{d} 7$ or 14 postpartum. Endometritis diagnosis was performed at $35 \pm 3$ DIM using the Metricheck device; the vaginal discharge was scored using a scale of 0 to $3(0=$ no secretion material retrieved or clear mucus, $1=$ flecks of purulent material within otherwise clear mucus; $2=$ less than $50 \%$ of purulent material in the vaginal discharge, $3=$ more than $50 \%$ of purulent material with or without fetid discharge); cows with a score of $\geq 2$ were considered as diagnosed with clinical endometritis. Displaced abomasum (DA) diagnosis was made by farm personnel and confirmed by veterinarians. Lameness was defined as cows with clinical manifestation of abnormal locomotion detected by farm personnel. Hyperketonemia (HYK) was defined as a plasma BHB concentration $\geq 1.2 \mathrm{mmol} / \mathrm{L}$ on $\mathrm{d} 3,7$, or 14 (McArt et al., 2012). Additionally, subclinical hypocalcemia $(\mathbf{S C H})$ was defined as a plasma Ca concentration $<7.5$ mg/dL (Goff et al., 1996; Neves et al., 2018).

Clinical mastitis was evaluated during the first 30 DIM and defined as the presence of abnormal milk, such as watery appearance or flakes and clots in milk during forestripping detected at each milking by trained farm employees. Once diagnosed in the milking parlor, the cow was immediately sorted on the DeLaval milking overview screen, which triggered her to be sorted through the DeLaval sort gate. Once the cow was sorted, a trained farm employee obtained a sample from the infected quarter(s). All mastitic cows were cultured using an on-farm culture system (Accumast, FERA Animal Health LLC, Ithaca, NY). On a daily basis, CM cases were scored by the research team using the traditional severity score system as mild (abnormal milk with no quarter swelling), moderate (abnormal milk with a swollen quarter), and severe (abnormal milk with a swollen quarter and systemic illness). Subclinical mastitis was evaluated by CMT at $10 \pm 3$ DIM. The CMT reaction of each quarter was recorded with a score ranging from 0 to 3 , with 0 indicating no reaction, 1 being a trace (approximately 200,000 to 500,000 
SCC), and 2 or 3 as CMT positive; SCM was defined as cows detected with a CMT score $\geq 1$. In addition, cows with SCC >200,000 from milk samples collected by DHI were defined as having SCM. A hospital pen trip was defined as cows moved by farm personnel to the hospital pen for therapy with antimicrobials, antiinflammatories, supportive therapy, or any therapy that required the milk or the meat to be withheld.

\section{Statistical Analysis}

To evaluate the effect of treatment on the proportion of cows affected by clinical diseases, the following diseases were combined for analysis: RP, metritis, puerperal metritis, endometritis, DA, lameness, and CM.

Descriptive statistics were performed in JMP Pro 11 (SAS Institute Inc., NC) using the ANOVA and chisquared functions for continuous and categorical data, respectively. For analyses of repeated measurements, such as white blood cells (WBC), PMN, monocytes (MONO), lymphocytes (LYM), percent neutrophils present in the reproductive tract, plasma metabolites, linear score, and milk yield and composition, we used general mixed linear models with the MIXED procedure of SAS (version 9.4; SAS/STAT, SAS Institute Inc.). The independent variables offered to the models were treatment, time, parity (primiparous vs. multiparous), BCS at enrollment, dystocia, stillbirth, and RT at enrollment. To evaluate the effect of treatment on blood cells, vaginal cytology, and milk production among cows diagnosed with metritis, puerperal metritis, metritisPM, mastitis, clinical diseases, and cows diagnosed pregnant or open at 120 DIM, the following variables were offered to the models: treatment, event, time, parity, dystocia, stillbirth, BCS at enrollment, and RT at enrollment. Two- and 3-way interaction terms between independent variables were offered to the models. For the hemogram data, baseline values of blood cell parameters were treated as covariate variables. Normality and homoscedasticity of residuals were assessed using residual plots. Several covariance structures were tested (unstructured, autoregressive 1, compound symmetry), and the one with the minimum Akaike information criterion was chosen. For all models, Tukey's honest significance test for multiple comparisons was used. Data are reported as least squares means \pm standard error of the mean unless otherwise stated.

The chi-squared test was used to compare the incidence of the evaluated periparturient diseases. For the chi-squared test, we followed the assumption that no cell should have an expected frequency of less than 5; when the assumption was not satisfied, Fisher's exact test was used. The effect of treatment on the odds ratio (OR) of binary response variables was analyzed by logistic regression using the GLIMMIX procedure of SAS and the fixed effects of treatment, parity, BCS at enrollment, RT at enrollment, and the interaction term treatment by parity were included as independent variables in the statistical models. A Poisson regression model was used to evaluate the effect of treatment on the number of clinical mastitis cases using the PROC GENMOD procedure in SAS. To ensure validity of the Poisson model, goodness of fit was evaluated with the Pearson Chi-squared test. Treatment, parity, and the interaction term treatment by parity were included as fixed effects. Controls were considered as the reference group.

The effect of treatment on the hazard of pregnancy and herd removal during the first 180 DIM as well as days to the first service during the first 120 DIM were analyzed by Cox's proportional hazard using the PHREG procedure in SAS. Variables offered to the models included treatment, parity, BCS at enrollment, and their interactions. To illustrate the effect of treatment on reproductive performance, herd removal, and days to first service, Kaplan-Meier survival analysis was carried out using MedCalc version 11.5.1.0 software (MedCalc Software, Ostend, Belgium). Body condition score loss was defined as BCS at calving minus BCS at d 35 and assessed using the GLIMMIX procedure of SAS. Colostrum concentrations of IgG, IgA, IgM, and lactoferrin and plasma minerals were analyzed with the GLIMMIX procedure of SAS. Lastly, multivariable analysis was conducted to assess the effect of treatment on pregnancy per AI (P/AI) at first service and pregnancy loss after first AI using the GLIMMIX procedure of SAS. Variables offered to the model included treatment, parity, BCS at enrollment, AI protocol, sire, inseminator, and the interaction term treatment by parity. For all models, variables and their respective interaction terms were retained in the model when $P \leq$ 0.15 . Significance was considered when $P \leq 0.05$ or a trend if $0.05<P \leq 0.10$.

\section{RESULTS}

\section{Descriptive Data}

Descriptive data per treatment group regarding the number of cows enrolled in the study, average parity, number of primiparous and multiparous, BCS at enrollment, RT at enrollment, length of the dry period in days for multiparous cows, 305-d mature-equivalent lactation yields, sire PTA for primiparous cows, days of 
Table 1. Descriptive data for cows enrolled in the study

\begin{tabular}{lccc}
\hline & \multicolumn{2}{c}{ Treatment (LSM \pm SEM) } & $\begin{array}{c}P \text {-value } \\
\text { Treatment }\end{array}$ \\
\cline { 2 - 3 } Item & Control & Pegbovigrastim & - \\
\hline Median parity & 2 & 2 & - \\
No. of primiparous & 120 & 118 & - \\
No. of multiparous & 303 & 299 & - \\
Total number & 423 & 417 & 0.85 \\
BCS at enrollment & $3.67 \pm 0.01$ & $3.68 \pm 0.01$ & 0.80 \\
Rectal temperature at enrollment, ${ }^{\circ} \mathrm{C}$ & $38.7 \pm 0.01$ & $38.7 \pm 0.01$ & 0.64 \\
Dry period of multiparous, d & $55.62 \pm 0.59$ & $56.01 \pm 0.59$ & 0.92 \\
305-ME, ${ }^{1}$ kg & $13901 \pm 116$ & $13840 \pm 117$ & 0.24 \\
Sire PTA for milk, kg & $881 \pm 39.64$ & $886 \pm 40.01$ & 0.98 \\
Days of gestation & $277.81 \pm 0.22$ & $277.46 \pm 0.22$ & 0.58 \\
Twins, \% & 1.42 & 1.44 & 0.84 \\
Male calf, $\%$ & 48.46 & 50.36 & 7.63 \\
Stillbirth, \% & 8.33 & & \\
\hline
\end{tabular}

${ }^{1} 305$-d mature-equivalent lactation yields.

gestation, and the incidences of twins, male calves, and stillbirth are presented in Table 1. No differences were detected in any of these variables (Table 1 ).

\section{Days from First to Second Administration of PEG}

Figure 1 illustrates the interval between the first (7 d before the expected day of parturition) and second dose (within $24 \mathrm{~h}$ after calving) of PEG. Ninety percent of the cows received the 2 doses of PEG within $14 \mathrm{~d}$ of one another (Figure 1A). On average, cows received both doses of PEG with an interval of $8.83 \mathrm{~d}$, with a standard deviation of $4.62 \mathrm{~d}$, and a range from 0 to $26 \mathrm{~d}$ (Figure 1A). The frequency distribution of the interval between the first and second dose of PEG was also evaluated by parity. Ninety percent of primiparous cows received the 2 doses of PEG within $14 \mathrm{~d}$ of one another (Figure 1B). On average, primiparous cows received the 2 doses of PEG with an interval of $8.62 \mathrm{~d}$, with a standard deviation of $4.29 \mathrm{~d}$, and a range from 0 to $19 \mathrm{~d}$ (Figure 1B). Ninety-one percent of multiparous cows received the 2 doses of PEG within $14 \mathrm{~d}$ of one another (Figure 1C). On average, multiparous cows received the 2 doses of PEG with an interval of $8.92 \mathrm{~d}$, with a standard deviation of $4.75 \mathrm{~d}$, and a range from 0 to $26 \mathrm{~d}$ (Figure 1C).

\section{Effect of PEG on Hemogram Parameters}

The effects of PEG on the concentration of WBC, LYM, PMN, and MONO are presented in Figure 2A to D. The Vet hemogram instrument used recorded numbers of PMN and did not differentiate between neutrophils, basophils, and eosinophils, although neutrophils represent over $90 \%$ of the PMN (George et al., 2010). Treatment affected $(P \leq 0.001)$ the concentrations of
WBC, LYM, PMN, and MONO. Compared with CTR, treated cows had greater $(P \leq 0.001)$ blood counts of $\mathrm{WBC}\left(\mathrm{PEG}=21.12 \pm 0.42 ; \mathrm{CTR}=9.90 \pm 0.41 \times 10^{3} /\right.$ $\mu \mathrm{L}), \mathrm{LYM}(\mathrm{PEG}=7.87 \pm 0.16 ; \mathrm{CTR}=4.10 \pm 0.16 \times$ $\left.10^{3} / \mu \mathrm{L}\right), \mathrm{PMN}(\mathrm{PEG}=10.41 \pm 0.25 ; \mathrm{CTR}=4.86 \pm$ $\left.0.25 \times 10^{3} / \mu \mathrm{L}\right)$, and MONO $(\mathrm{PEG}=2.81 \pm 0.07$; CTR $\left.=0.95 \pm 0.07 \times 10^{3} / \mu \mathrm{L}\right)$ at $0,3,7$, and $14 \mathrm{~d}$ relative to the first PEG administration (Figure 2A-D).

Concentrations of WBC, LYM, PMN, and MONO were evaluated for cows diagnosed with and without metritis-PM and mastitis, and for open and pregnant cows at 120 DIM among and within treatment groups (Figure 3A-C and Supplemental Table S1; https://doi .org/10.3168/jds.2018-14869). Overall, PEG cows had greater $(P \leq 0.001) \mathrm{WBC}$, LYM, and MONO when compared with CTR cows, irrespective of the health condition (metritis-PM, mastitis, no metritis-PM, or no mastitis) or reproductive status (pregnant or open). Cows treated with PEG and diagnosed with metritisPM had smaller $(P \leq 0.05)$ circulating WBC, PMN, LYM, and MONO on d 3 compared with PEG cows without metritis-PM (Figure 3A). Furthermore, PEG cows diagnosed with metritis-PM had smaller $(P \leq$ 0.05) WBC and PMN on d 7 compared with PEG nonmetritic cows (Figure 3A). Additionally, WBC concentration on d 14 tended to be smaller $(P \leq 0.10)$ in PEG-metritic cows when compared with nonmetritic PEG-treated cows (Figure 3A). Relative to cows diagnosed with mastitis and treated with PEG, PEG cows without mastitis tended to have smaller $(P \leq$ $0.10) \mathrm{WBC}$ and LYM and MONO concentrations $(P$ $\leq 0.05)$ on $\mathrm{d} 0$ (Figure 3B). In addition, PEG cows diagnosed with mastitis had smaller $(P \leq 0.05)$ WBC, PMN, LYM, and MONO on d 3 when compared with PEG nonmastitic cows (Figure 3B). Lastly, pregnant cows from the PEG group had greater $(P \leq 0.05)$ LYM 

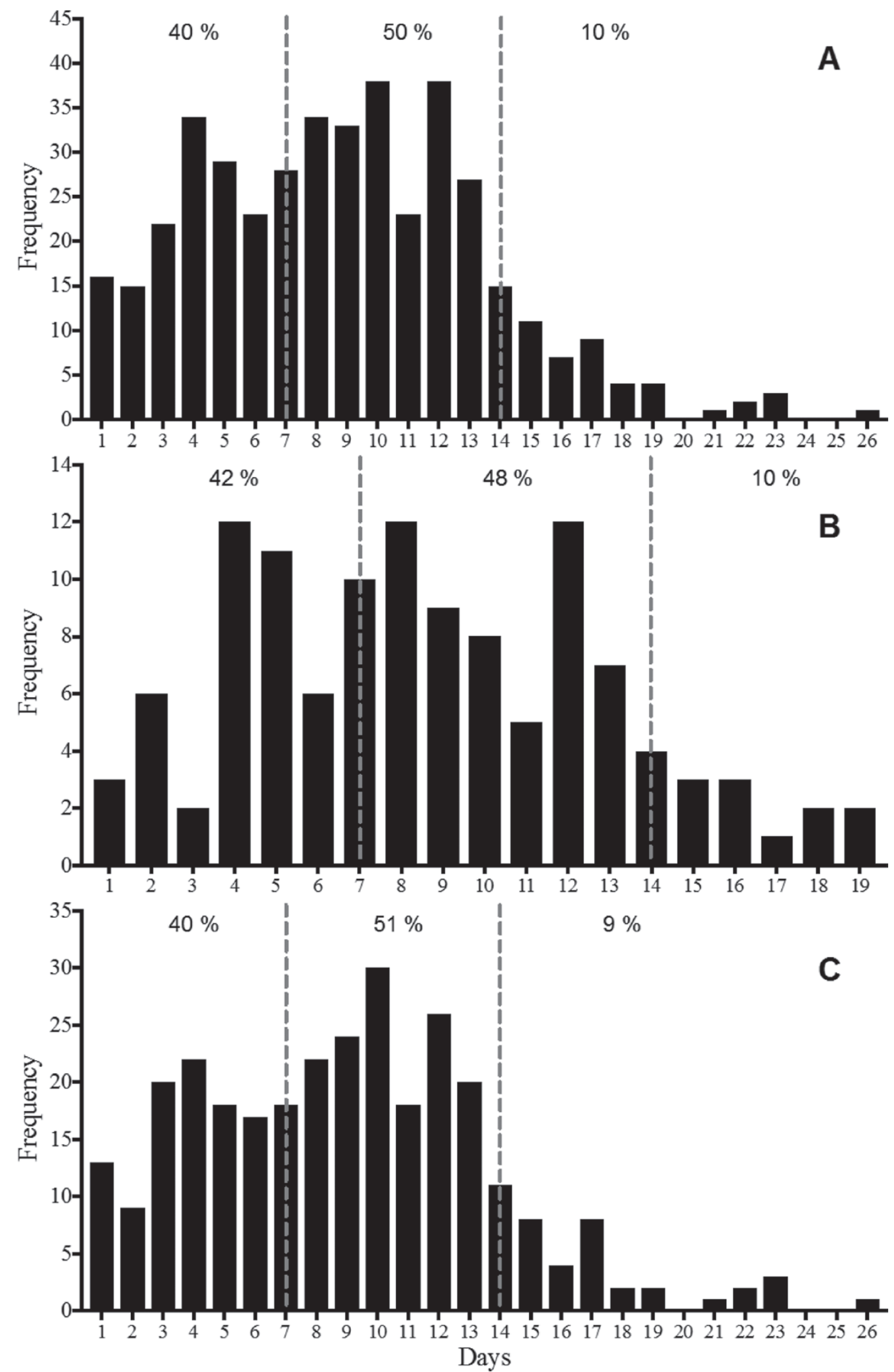

Figure 1. Days from the first to second administration of pegbovigrastim in all treated cows (A; mean $=8.83 ;$ range $=1$ to $26 \mathrm{~d} ; \mathrm{SD}=4.62$; median $=9)$, treated primiparous cows $(\mathrm{B}$; mean $=8.62$; range $=1$ to $19 \mathrm{~d} ; \mathrm{SD}=4.29$; median $=8)$, and treated multiparous cows $(\mathrm{C}$; mean $=8.92 ;$ range $=1$ to $26 \mathrm{~d} ; \mathrm{SD}=4.75 ;$ median $=9)$. 
and MONO concentrations on d 3 compared with PEG open cows (Figure 3C). Statistical differences were not observed for hemogram parameters within CTR cows for any health condition (metritis-PM, mastitis, no metritis-PM, or no mastitis) or for reproductive status (pregnant or open; Figure 3A-C).

Counts of WBC, LYM, PMN, and MONO were also evaluated for cows diagnosed with and without clinical diseases. Cows treated with PEG had greater $(P \leq$ $0.002) \mathrm{WBC}$ and PMN concentrations when compared with CTR cows, regardless of the health condition (clinical diseases or no clinical disease); more detailed information can be found in Supplemental Figure S1 and Supplemental Table S1 (https://doi.org/10.3168/ jds.2018-14869).
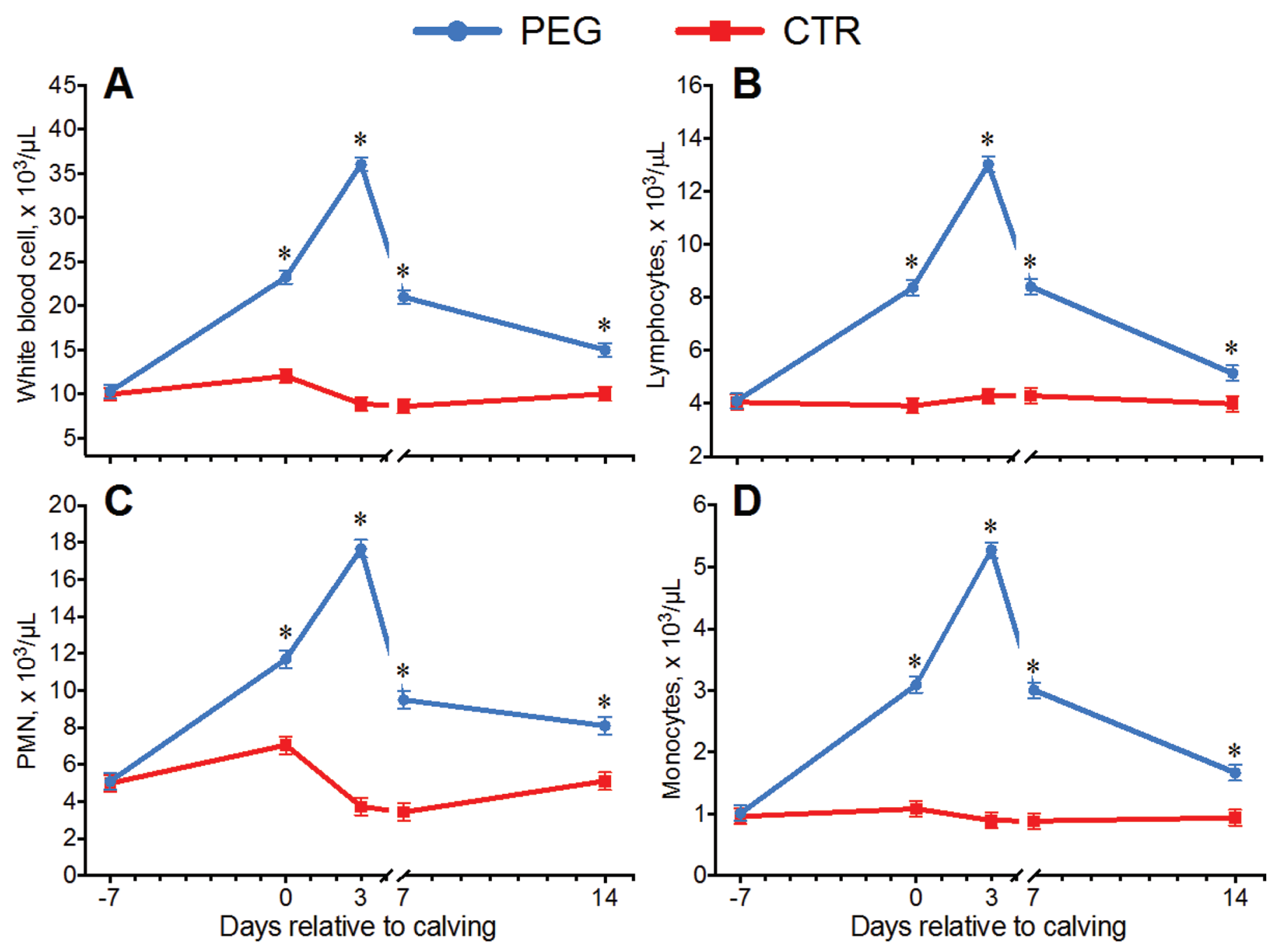

\section{Effect of PEG on Plasma Metabolites and Minerals}

Treatment with PEG did not affect the plasma concentrations of NEFA, BHB, and haptoglobin (Figure 4). No differences were observed in plasma minerals between the PEG and CTR groups (Supplemental Table S2; https://doi.org/10.3168/jds.2018-14869).

\section{Effect of PEG on Vaginal Neutrophil Counts}

Treatment with PEG did not affect the relative counts of neutrophils present in the vaginal mucosa (Figure 5A). We also evaluated the effect of treatment on the relative counts of neutrophils present in the vaginal mucosa among cows diagnosed with metritis-PM

Figure 2. White blood cell (A), lymphocyte (B), PMN (C), and monocyte (D) concentrations of cows treated with pegbovigrastim (PEG, $\mathrm{n}=102)$ and control $(\mathrm{CTR}, \mathrm{n}=103)$ cows at $-7,0,3,7$, and $14 \mathrm{~d}$ relative to parturition. Results are presented as LSM \pm SEM. $* P \leq 0.001$. Color version available online. 
USE OF PEGBOVIGRASTIM IN HOLSTEIN COWS
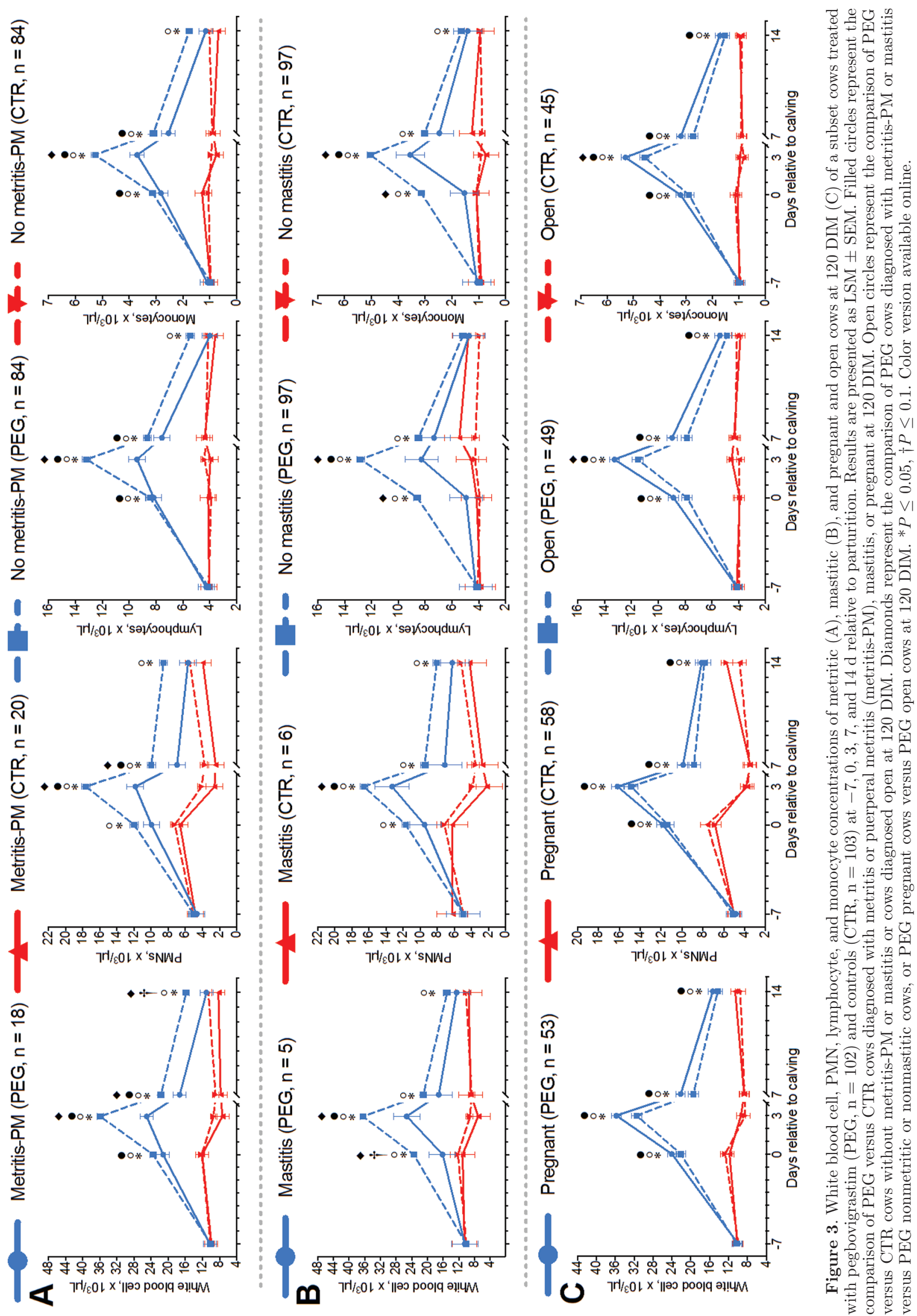

Journal of Dairy Science Vol. 101 No. 12, 2018 

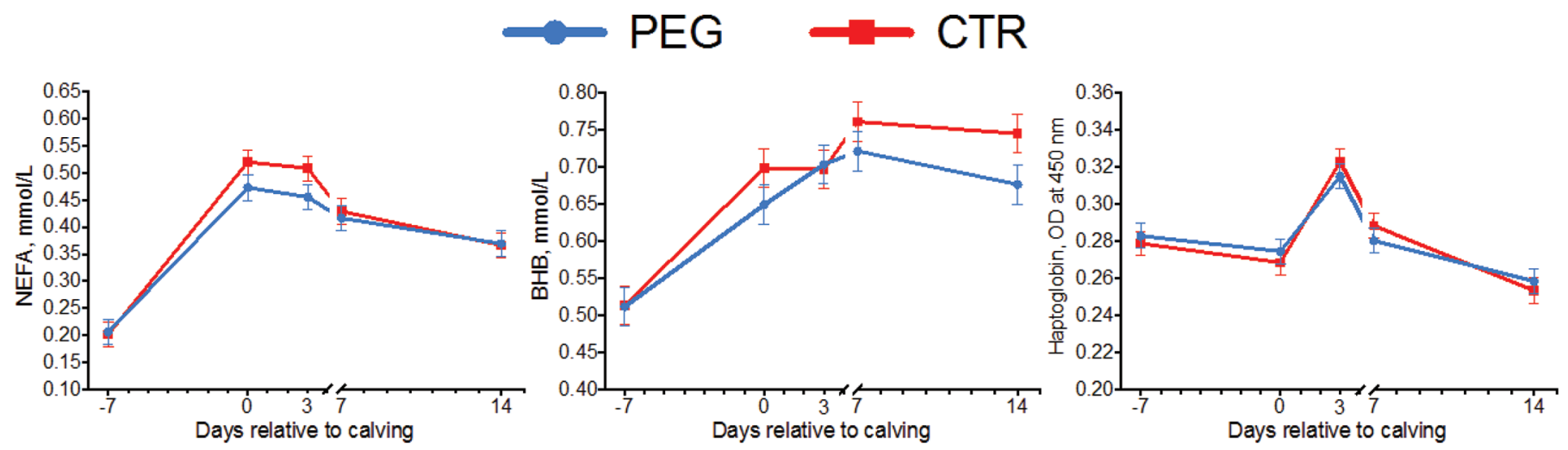

Figure 4. Plasma concentrations of nonesterified fatty acids (NEFA), BHB, and haptoglobin [optical density (OD) units] of cows treated with pegbovigrastim (PEG, $\mathrm{n}=102$ ) and controls $(\mathrm{CTR}, \mathrm{n}=103)$ at -7 , and $0,3,7$, and $14 \mathrm{~d}$ relative to parturition. Results are presented as $\mathrm{LSM} \pm \mathrm{SEM}$. Color version available online.

(Figure 5B). We detected a treatment by metritis-PM interaction $(P=0.003)$, where PEG cows diagnosed with metritis-PM tended to have more relative neutrophil counts compared with CTR cows with metritis-PM (PEG-metritis-PM, $55.75 \pm$ 5.01; CTR-metritis-PM, $43.38 \pm 4.98 \% ; P=0.08)$. Additionally, PEG cows diagnosed with metritis-PM had more $(P \leq 0.05)$ relative counts of neutrophils on $\mathrm{d} 7$ than CTR cows with metritis-PM for the same day (Figure 5B). Cows diagnosed with metritis-PM tended $(P \leq 0.10)$ and had greater $(P \leq 0.05)$ relative counts of neutrophils at $\mathrm{d} 0$ and 7 compared with cows without metritis-PM (Supplemental Figure S2A; https://doi.org/10.3168/ jds.2018-14869). Additionally, cows diagnosed with endometritis had greater $(P \leq 0.05)$ relative counts of neutrophils at d 35 compared with cows without endometritis (Supplemental Figure S2B). We also evaluated the relative counts of neutrophil present in the vaginal mucosa of pregnant and nonpregnant cows at 120 DIM at d 0,7 , and 35; pregnant cows had greater percentage of neutrophils at $\mathrm{d} 0(P<0.01)$ and $7(P<0.001)$ than nonpregnant cows (Supplemental Figure S2C).

\section{Effect of PEG on Periparturient Diseases and Removal from the Herd}

The effects of PEG on the evaluated periparturient diseases are presented in Table 2. Treatment did not
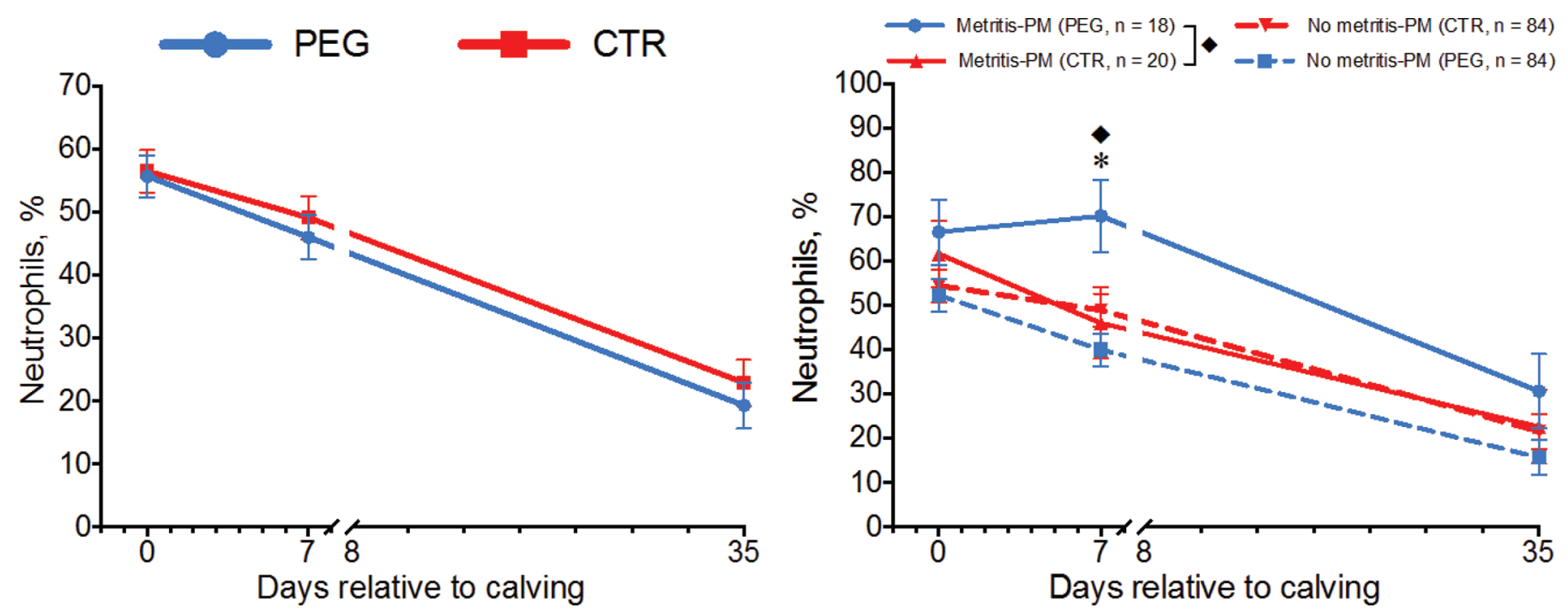

Figure 5. Percentage of neutrophils identified in the vagina by cytobrush for cows treated with pegbovigrastim (PEG, $\mathrm{n}=102)$ and controls (CTR, $\mathrm{n}=103)$ at 0,7 , and 35 d relative to parturition $(\mathrm{A})$. Percentage of neutrophils of PEG and CTR cows diagnosed with metritis or puerperal metritis (metritis-PM) at 0,7 , and $35 \mathrm{~d}$ relative to parturition (B). Results are presented as LSM $\pm \mathrm{SEM}$. ${ }^{*} P \leq 0.05$. The diamond represents the comparison of PEG cows diagnosed with metritis-PM versus CTR cows with metritis-PM. Color version available online. 
affect the incidence of stillbirth, dystocia, RP, metritis, puerperal metritis, metritis-PM, endometritis, CM, or SCM at d 7, 10, 14, 21, and 28 or at first and second DHI test. No differences were detected on postpartum fever between the PEG and CTR groups. A treatment by parity interaction $(P=0.05)$ was observed for HYK incidence. Relative to CTR, primiparous cows treated with PEG tended $(P=0.08)$ to have lower odds of HYK $(\mathrm{OR}=0.57,95 \% \mathrm{CI}=0.23$ to 1.42$)$. Additionally, $\mathrm{PEG}$ cows had higher odds $(P=0.05)$ of being diagnosed with DA compared with CTR cows $(\mathrm{OR}=8.27,95 \%$ $\mathrm{CI}=1.02$ to 66.66$)$. The odds of lameness were higher $(P=0.008)$ for PEG cows when compared with CTR cows $(\mathrm{OR}=1.79,95 \% \mathrm{CI}=1.16$ to 2.76$)$ in the first 30 DIM, but were not different $(P=0.13)$ by 60 DIM $(\mathrm{OR}=1.32,95 \% \mathrm{CI}=0.91$ to 1.92$)$. The incidence of SCH was not affected by treatment (13.1 vs. $12.1 \%$ for PEG vs. CTR; $P=0.88)$. Overall, treatment with PEG increased $(P=0.03)$ the incidence of clinical diseases (46.04 vs. $35.95 \%$ for PEG vs. CTR). Cows treated with PEG had higher odds of being diagnosed with 1 or more clinical diseases compared with CTR cows (OR $=1.39,95 \% \mathrm{CI}=1.02$ to 1.90 ).

We also evaluated the effect of treatment on the incidences of CM by pathogen and lameness by lesion type (Table 3). Treatment with PEG did not affect the incidence of CM by pathogen. However, multiparous cows treated with PEG had a higher $(P=0.02)$ incidence of foot rot when compared with controls (2.46 vs. $0.00 \%$ for PEG vs. CTR). Moreover, multiparous cows treated with PEG tended to have $(P=0.06)$ a higher incidence of white line disease than CTR cows (3.47 vs. $6.26 \%$ for PEG vs. CTR). Furthermore, PEG multiparous cows had $(P=0.03)$ a higher incidence of lameness with no lesion detected when compared with CTR multiparous cows (10.21 vs. $4.94 \%$ for PEG vs. CTR). Additionally, the severity of the mastitis score did not differ between the PEG and CTR groups (data not shown).

A Poisson regression model was used to evaluate the effect of treatment on the number of mastitis cases dur-

Table 2. Incidence (\%) of periparturient diseases of cows treated with pegbovigrastim $(\mathrm{PEG}, \mathrm{n}=417)$ and controls $(\mathrm{CTR}, \mathrm{n}=423)$ by parity (primiparous: PEG, $\mathrm{n}=118, \mathrm{CTR}, \mathrm{n}=120$; multiparous: PEG, $\mathrm{n}=299, \mathrm{CTR}, \mathrm{n}=303)^{1}$

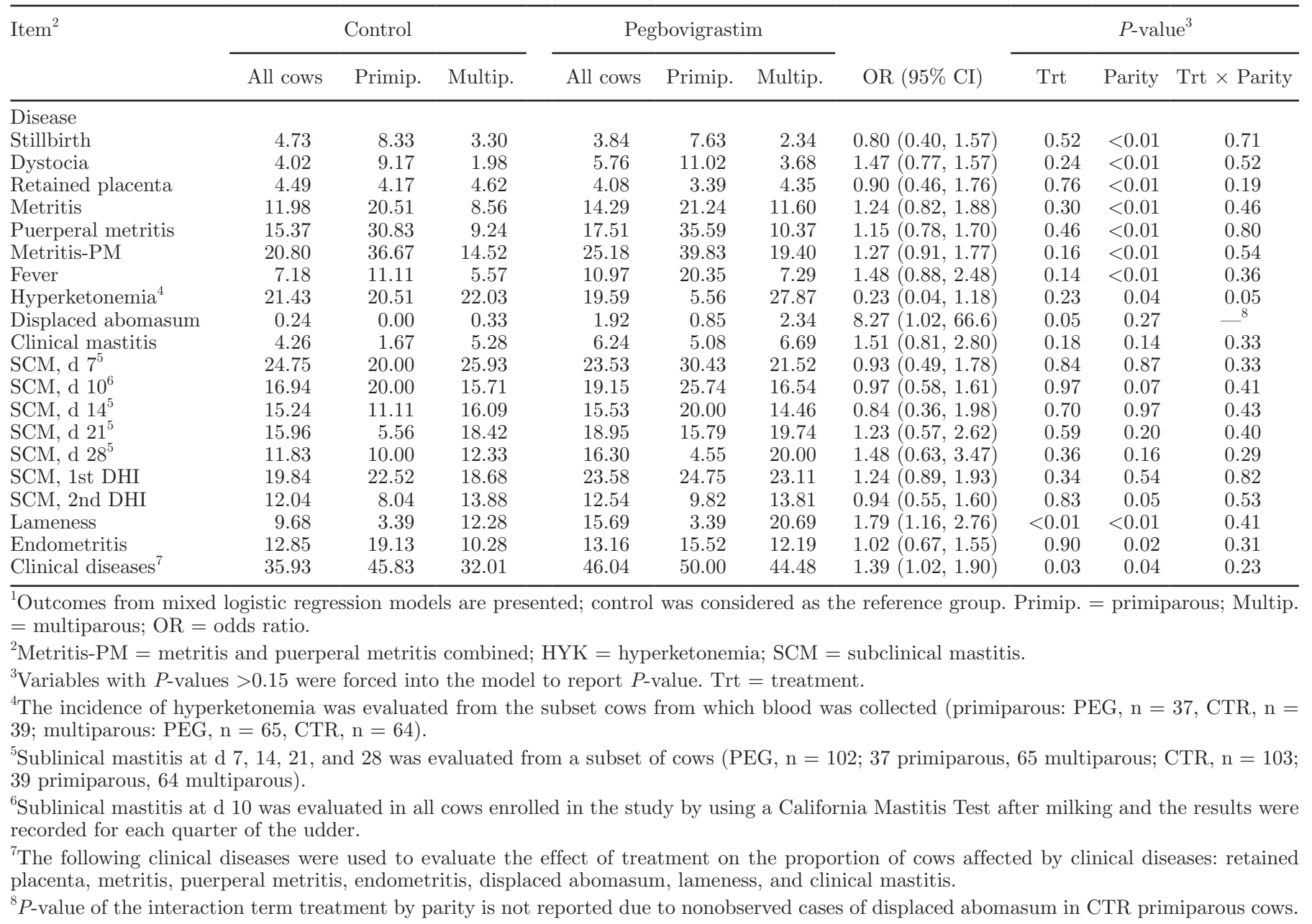


Table 3. Incidence (\%) of clinical mastitis by pathogen and lameness by lesion type during the first $30 \mathrm{~d}$ after calving of cows treated with pegbovigrastim (PEG, $\mathrm{n}=417$ ) and controls $(\mathrm{CTR}, \mathrm{n}=423$ ) by parity (primiparous: $\mathrm{PEG}, \mathrm{n}=118$; CTR, $\mathrm{n}=120 ;$ multiparous: PEG, $\mathrm{n}=$ $299 ; \mathrm{CTR}, \mathrm{n}=303)^{1}$

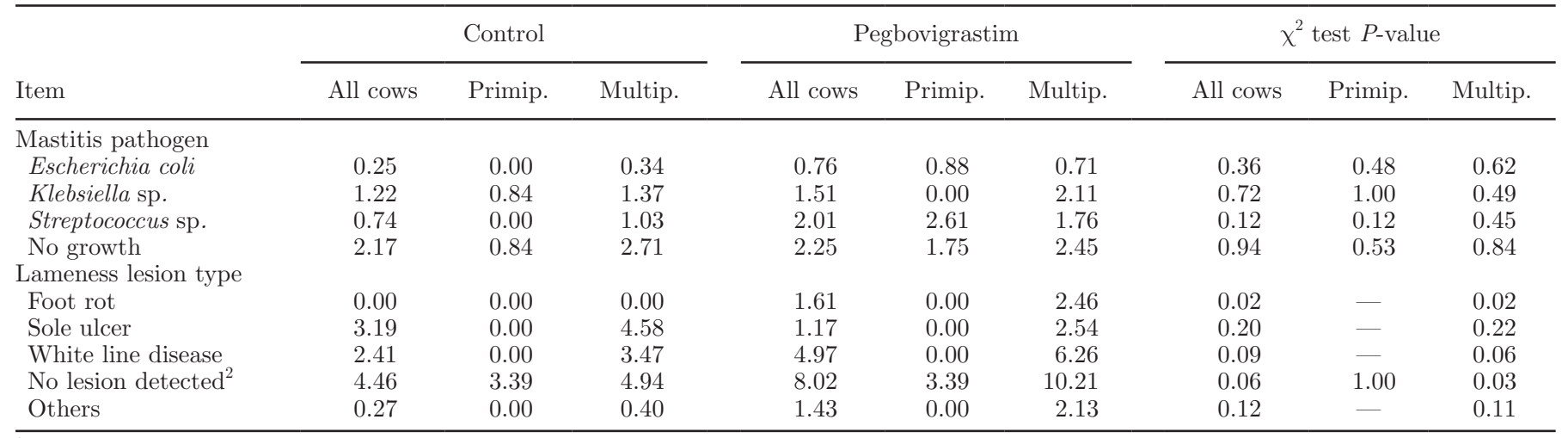

${ }^{1}$ Primip. = primiparous; Multip. = multiparous.

${ }^{2}$ No lesion detected was defined as cows being diagnosed lame with no observed macroscopic lesion in the feet.

ing the first $30 \mathrm{~d}$ postpartum $(\mathrm{PEG}=26 ; \mathrm{CTR}=18)$. No differences $(P=0.16)$ were observed (risk ratio $=$ $1.52,95 \% \mathrm{CI}=0.84$ to 2.73$)$.

A logistic regression model was used to assess the effect of treatment on the odds of experiencing a hospital pen trip within the first $30 \mathrm{~d}$ postpartum. No differences $(P=0.13)$ were observed between the PEG and CTR groups ( $\mathrm{OR}=1.44,95 \% \mathrm{CI}=0.90$ to 2.29$)$. Lastly, treatment did not alter $(P=0.66)$ the hazard of culling during the first 180 DIM (hazard ratio $=0.88$, $95 \%$ CI $=0.59$ to 1.28; Supplemental Figure S3; https: //doi.org/10.3168/jds.2018-14869).

\section{Effect of PEG on Linear Scores}

The effect of PEG on SCS at 7, 14, 21, and $28 \mathrm{~d}$ relative to calving and at first, second, and third DHI test is illustrated in Figure 6. Treatment with PEG did not affect SCS.

\section{Effect of PEG on Reproductive Performance and BCS}

Treatment did not alter $(P=0.92)$ the hazard of pregnancy during the first 180 DIM (hazard ratio $=$ 0.99, $95 \%$ CI $=0.84$ to 1.7; Supplemental Figure S3; https://doi.org/10.3168/jds.2018-14869). The median calving-to-conception interval for PEG and CTR cows was 103 and $104 \mathrm{~d}$, respectively. No differences were observed between the PEG and CTR groups for pregnancy per AI at first service (34.3 vs. $28.8 \%$ for PEG vs. CTR; $P=0.11)$. Moreover, no differences were detected between the PEG and CTR groups on pregnancy loss after first postpartum AI (8.9 vs. $11.4 \%$ for PEG vs. CTR; $P=0.51$ ). Furthermore, treatment did not alter $(P=0.66)$ the hazard of being inseminated within the first 120 DIM (hazard ratio $=1.03,95 \%$ CI $=0.89$ to 1.19; Supplemental Figure S3). Body condition score loss from calving until $35 \mathrm{~d}$ after parturition was not affected by treatment $(P=0.88)$.

\section{Effect of PEG on Milk Yield and Composition}

The effects of PEG treatment on weekly milk averages (first 12 wk of lactation) and ECM, FCM, and milk components for the first 3 mo of lactation are presented in Table 4. A significant interaction between treatment and parity was detected for milk production $(P \leq 0.03)$; primiparous cows treated with PEG produced $1.6 \mathrm{~kg} / \mathrm{d}$ more milk compared with controls, and no differences were detected between the PEG and CTR groups for multiparous cows. No differences were observed on ECM, FCM, and milk composition between the PEG and CTR groups (Table 4).

Daily milk weights for the first 30 DIM were used to evaluate the effect of treatment on cows diagnosed with $\mathrm{CM}$, lameness within the first 30 DIM, metritis, puerperal metritis, and clinical diseases (Table 5). No differences were observed between treatment groups for cows diagnosed with $\mathrm{CM}$ or clinical diseases. Among cows diagnosed lame, PEG cows tended to produce more milk $(P=0.09)$ than CTR. Multiparous cows treated with PEG and diagnosed with metritis produced more milk $(P=0.01)$ than CTR.

\section{Effect of PEG on Colostrum Immunoglobulin and Lactoferrin concentrations}

Treatment did not affect the concentrations of $\operatorname{IgA}$, IgM, IgG, and lactoferrin in colostrum (Figure 7). 


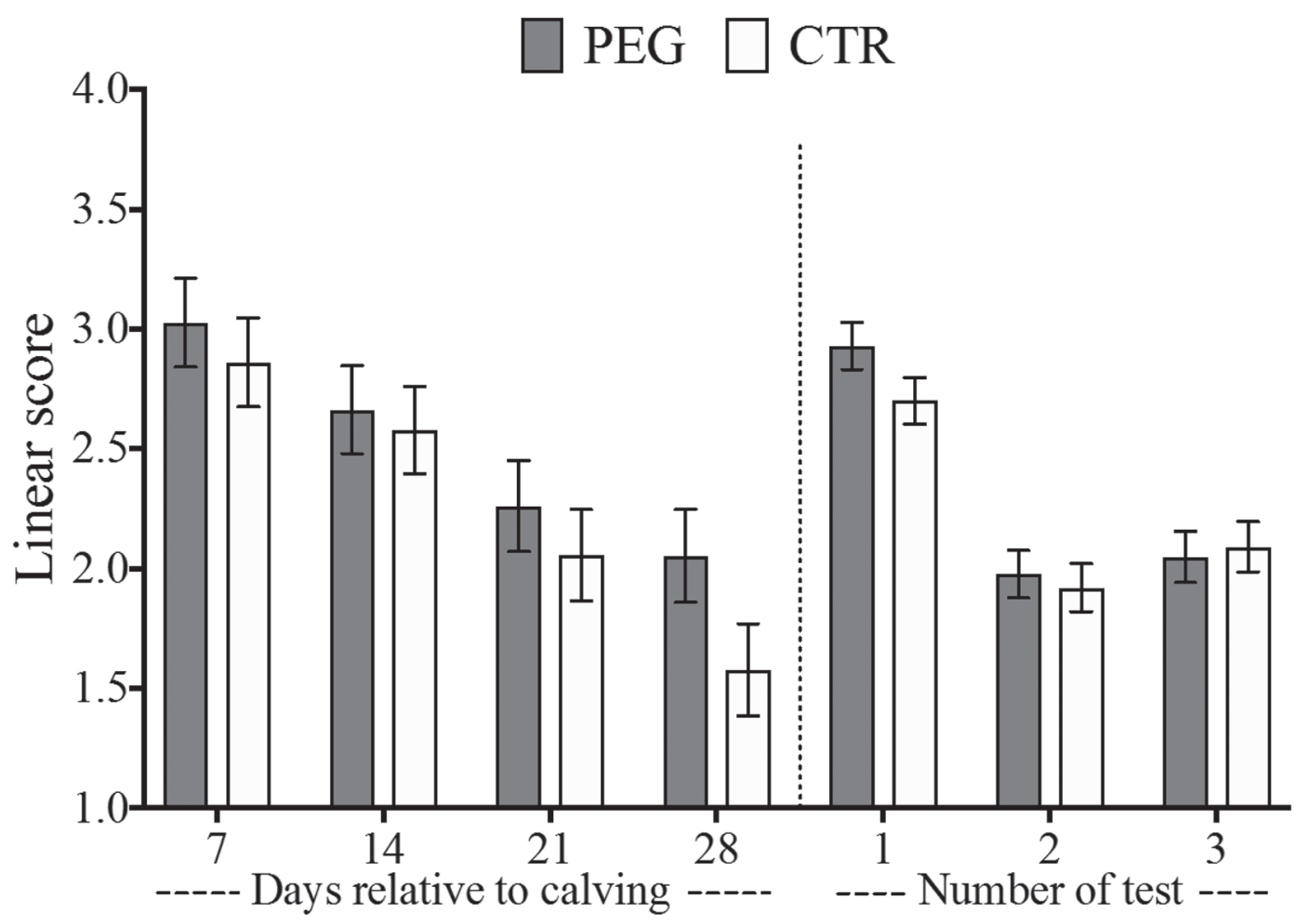

Figure 6. Linear scores of cows treated with pegbovigrastim (PEG) and controls (CTR) at 7, 14, 21, and 28 d relative to parturition [left side of the dotted line (PEG, $\mathrm{n}=110 ; \mathrm{CTR}, \mathrm{n}=119)$ ], and at first, second, and third DHI test [right side of the dotted line (PEG, $\mathrm{n}=417$; $\mathrm{CTR}, \mathrm{n}=423)]$. Results are presented as LSM \pm SEM.

\section{DISCUSSION}

In support of our initial hypothesis, cows treated with PEG exhibited a 3 - to 4-fold increase in circulating WBC compared with CTR cows. However, treatment did not alter the incidence of mastitis (clinical or subclinical) or uterine diseases and did not affect reproductive performance. Cows treated with PEG were more likely to be diagnosed with 1 or more of the evaluated clinical diseases when compared with CTR cows. Additionally, we observed that primiparous cows treated with PEG produced more milk during the first 12 wk after parturition than CTR primiparous cows; however, PEG did not affect ECM, FCM, and milk components. The present study identified, for the first time, a detrimental effect of PEG treatment on postpartum lameness and DA.

Polymorphonuclear cells are the main cell line of defense involved in bacterial clearance after uterine (Hussain, 1989) and mammary gland (Paape et al., 2002) infection and play a major role in placental release (Kimura et al., 2002). However, peripheral blood PMN function of periparturient dairy cows is impaired relative to nonparturient cows (Kehrli et al., 1989; Cai et al., 1994). Moreover, blood neutrophil function begins to decline before parturition and slowly returns to prepartum levels approximately 4 wk postpartum (Kehrli et al., 1989; Goff and Horst, 1997). Thus, increasing WBC in periparturient dairy cows could be a good strategy to mitigate the immunosuppression observed during the transition from late gestation through early lactation.

Our results are in accordance with previous studies showing that PEG treatment increases circulating WBC (Kimura et al., 2014; Canning et al., 2017; McDougall et al., 2017). More specifically, our finding of increased blood PMN agrees with the literature; however, discrepant results have been reported for MONO and LYM concentrations (Kimura et al., 2014; McDougall et al., 2017). Kimura et al. (2014) observed no differences between PEG-treated and untreated cows in terms of MONO and LYM numbers. In contrast, a study by McDougall et al. (2017) reported a significant increase in MONO and LYM counts. Moreover, similar increases in MONO and LYM concentrations were observed in humans treated with G-CSF (Pollmächer et al., 1996; Reyes et al., 1999). Based on our results and those reported by McDougall et al. (2017), we concluded that PEG treatment increases PMN, MONO, and LYM numbers in Holstein cows. 


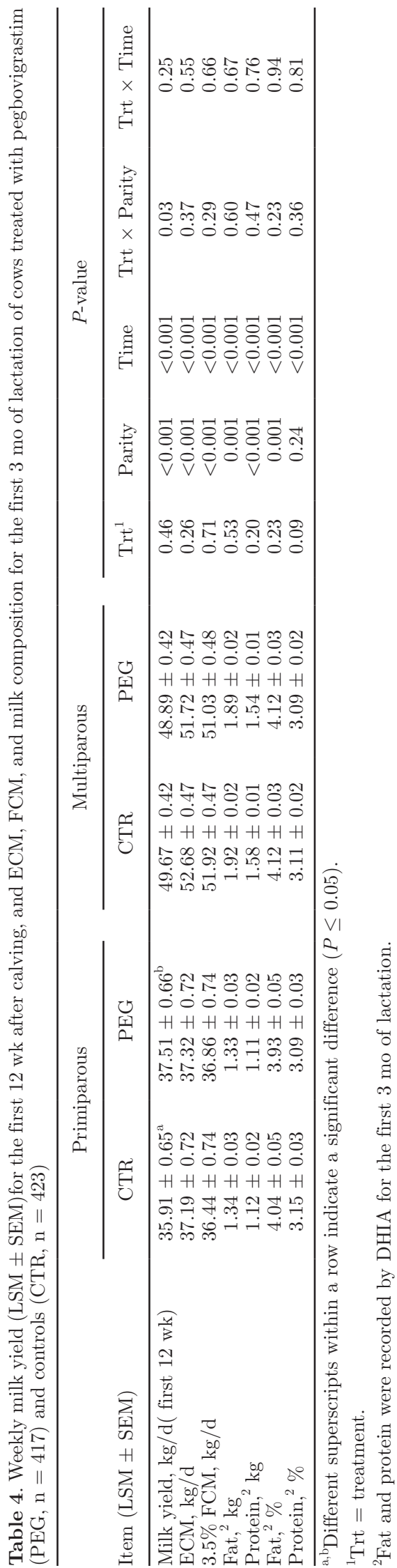

Neutrophils are the first line of defense to arrive in the mammary gland once pathogen invasion occurs. Therefore, the ability of the mammary gland to counteract bacterial infection relies mainly on (1) circulating neutrophils and their ability to enter the alveoli lumen and (2) their phagocytic and killing capacity (Ezzat Alnakip et al., 2014). The peripartum administration of PEG has been associated with a decreased incidence of CM in recent studies (Hassfurther et al., 2015; Canning et al., 2017; Ruiz et al., 2017); however, in the present study, the incidence of CM and SCM did not differ between the PEG and CTR groups. In the studies conducted by Canning et al. (2017) and Hassfurther et al. (2015), the incidence of CM in the first 30 DIM for control cows was 23 and $34 \%$, respectively. Herein, the incidence of CM in the first 30 DIM for the CTR group was much lower $(4.26 \%)$; thus, it is possible that the lack of a preventive effect of PEG on postpartum $\mathrm{CM}$ in our study was due to the very low incidence of CM during the first 30 DIM. However, in the study conducted by Ruiz et al. (2017), the incidence of CM was about $4.9 \%$ and the administration of PEG significantly reduced the incidence of CM. Nevertheless, in the present study, the incidence of CM was numerically higher in the PEG group when compared with CTR group and no effect of treatment on SCS was identified. In support of our findings, Canning et al. (2017) reported no effect of PEG treatment on SCC.

It is also possible that the key to preventing the occurrence of $\mathrm{CM}$ during the early postpartum period would be to increase the phagocytic and killing ability of neutrophils and not simply increasing their counts in blood. In support of this theory, recent studies have been shown that neutrophil phagocytic activity, oxidative burst, and MPO function is not affected by PEG treatment (Kimura et al., 2014; McDougall et al., 2017).

The relationship between uterine diseases and neutrophil function has been the topic of several studies (Gunnink, 1984a,b; Kimura et al., 2002). Kimura et al. (2002) demonstrated that the neutrophils of cows affected with RP had impaired neutrophil function, and these differences were identified as early as $10 \mathrm{~d}$ before parturition. A recent study evaluated the proportion of neutrophils in the uterine lumen during the early postpartum and its associations with uterine bacterial infection and reproductive performance (Gilbert and Santos, 2016). Cows with the greatest influx of neutrophils into the uterus in the immediate postpartum period were associated with improved uterine health and reproductive performance. In agreement with the published literature, our study also identified that early influx of neutrophils into the reproductive tract mucosa was associated with increased reproductive performance. However, PEG administration did not induce an 
early influx of neutrophils into the reproductive tract and did not improve uterine health and reproductive performance. Curiously, we observed that the relative counts of neutrophils of cows affected with metritis-PM previously treated with PEG were significantly higher at $\mathrm{d} 7$ when compared with those of CTR cows affected with metritis-PM. Therefore, the higher proportion of neutrophils observed in PEG-treated cows with metritis-PM may be a result of blood neutrophils migrating into the uterine lumen in response to activated chemokine signaling due to bacterial infection.

In our study, the incidence of metritis and puerperal metritis were not affected by PEG. Conversely, Ruiz et al. (2017) observed a $17 \%$ increase in metritis incidence with PEG treatment. In their study, cows affected with metritis were recognized by abnormal uterine discharge (smelly and watery) without (mild metritis) or with (severe metritis) the presence of systemic clinical signs such as fever, depression, or lack of appetite within 21 $\mathrm{d}$ postpartum. The criteria we used to define a cow affected with metritis-PM (watery and smelly red-brown uterine discharge with or without systemic illness) is comparable to the one used in the study conducted by Ruiz et al. (2017). Similarly, we observed that cows treated with PEG had a numerical increase $(P=$ 0.16 ) of $20 \%$ in metritis-PM incidence when compared with CTR cows. Herein, our sample size was not large enough to detect significant differences in metritis-PM incidence; however, our results are in alignment with the results reported by Ruiz et al. (2017). It was suggested that a more robust uterine inflammatory response, triggered by a rise in neutrophil numbers and functions, could be the reason more cows exhibited clinical metri- tis, and that future studies were needed to characterize the PMN cells present in the uterus of cows affected with metritis (Ruiz et al., 2017). In support of that notion, we observed that cows diagnosed with metritisPM and treated with PEG had higher relative counts of neutrophils in the reproductive tract mucosa when compared with CTR cows with metritis-PM.

Furthermore, we observed that multiparous cows diagnosed with metritis and treated with PEG produced more milk than CTR multiparous cows with metritis. These findings are in alignment with the study conducted by Ruiz et al. (2017), in which multiparous cows diagnosed with metritis and treated with PEG showed a higher milk yield than untreated controls. However, in the current study, when milk yield was evaluated between treatment groups within cows diagnosed with metritis-PM, the administration of PEG did not alter milk yield. Ruiz et al. (2017) also reported that PEGtreated multiparous cows that developed CM tended to produce more milk than CTR mastitic cows. Nevertheless, in the present study, milk yield was not affected by PEG when cows experienced an event of CM.

Interestingly, we found that cows treated with PEG had higher odds of being diagnosed with 1 or more of the evaluated clinical diseases compared with CTR. Based on the detected increase of neutrophils in the vaginal mucosa of PEG cows with metritis-PM compared with CTR cows with metritis-PM, as well as the higher blood PMN in treated cows than CTR cows, it is possible that cows treated with PEG and experiencing a bacterial infection might have an increased migration of neutrophils to the site of infection, which could lead to exacerbated clinical signs. Therefore, the administra-

Table 5. Milk yield (LSM \pm SEM) for the first 30 DIM $(\mathrm{kg} / \mathrm{d})$ of cows treated with pegbovigrastim (PEG) and controls (CTR) diagnosed with clinical mastitis, lame in the first 30 DIM, metritis, puerperal metritis, or both combined (metritis-PM), and clinical diseases

\begin{tabular}{|c|c|c|c|c|c|}
\hline \multirow[b]{2}{*}{ Item } & \multicolumn{2}{|c|}{$\mathrm{n}$} & \multicolumn{3}{|c|}{ Milk yield, kg/d (first 30 DIM) } \\
\hline & CTR & PEG & CTR & PEG & $P$-value \\
\hline \multicolumn{6}{|c|}{ Clinical mastitis } \\
\hline All cows ${ }^{1}$ & 16 & 26 & $32.50 \pm 2.43$ & $33.67 \pm 1.84$ & 0.66 \\
\hline \multicolumn{6}{|l|}{ Lameness } \\
\hline All cows ${ }^{1}$ & 39 & 64 & $34.91 \pm 1.24$ & $36.94 \pm 1.17$ & 0.09 \\
\hline \multicolumn{6}{|l|}{ Metritis } \\
\hline Primiparous & 24 & 24 & $27.85 \pm 0.87$ & $28.50 \pm 0.88$ & 0.59 \\
\hline Multiparous & 25 & 34 & $37.61 \pm 1.26$ & $41.78 \pm 1.06$ & 0.01 \\
\hline \multicolumn{6}{|c|}{ Puerperal metritis } \\
\hline Primiparous & 37 & 42 & $28.04 \pm 0.85$ & $29.95 \pm 0.81$ & 0.50 \\
\hline Multiparous & 28 & 31 & $40.82 \pm 0.98$ & $41.13 \pm 0.94$ & 0.82 \\
\hline \multicolumn{6}{|l|}{ Metritis-PM } \\
\hline Primiparous & 44 & 47 & $28.33 \pm 0.54$ & $29.20 \pm 0.54$ & 0.65 \\
\hline Multiparous & 44 & 58 & $40.40 \pm 0.70$ & $41.46 \pm 0.61$ & 0.67 \\
\hline \multicolumn{6}{|c|}{ Clinical diseases } \\
\hline Primiparous & 55 & 59 & $25.57 \pm 0.73$ & $26.48 \pm 0.71$ & 0.37 \\
\hline Multiparous & 97 & 133 & $38.55 \pm 0.55$ & $38.93 \pm 0.47$ & 0.60 \\
\hline
\end{tabular}

${ }^{1}$ Milk yield was not evaluated by parity due to small sample size. 


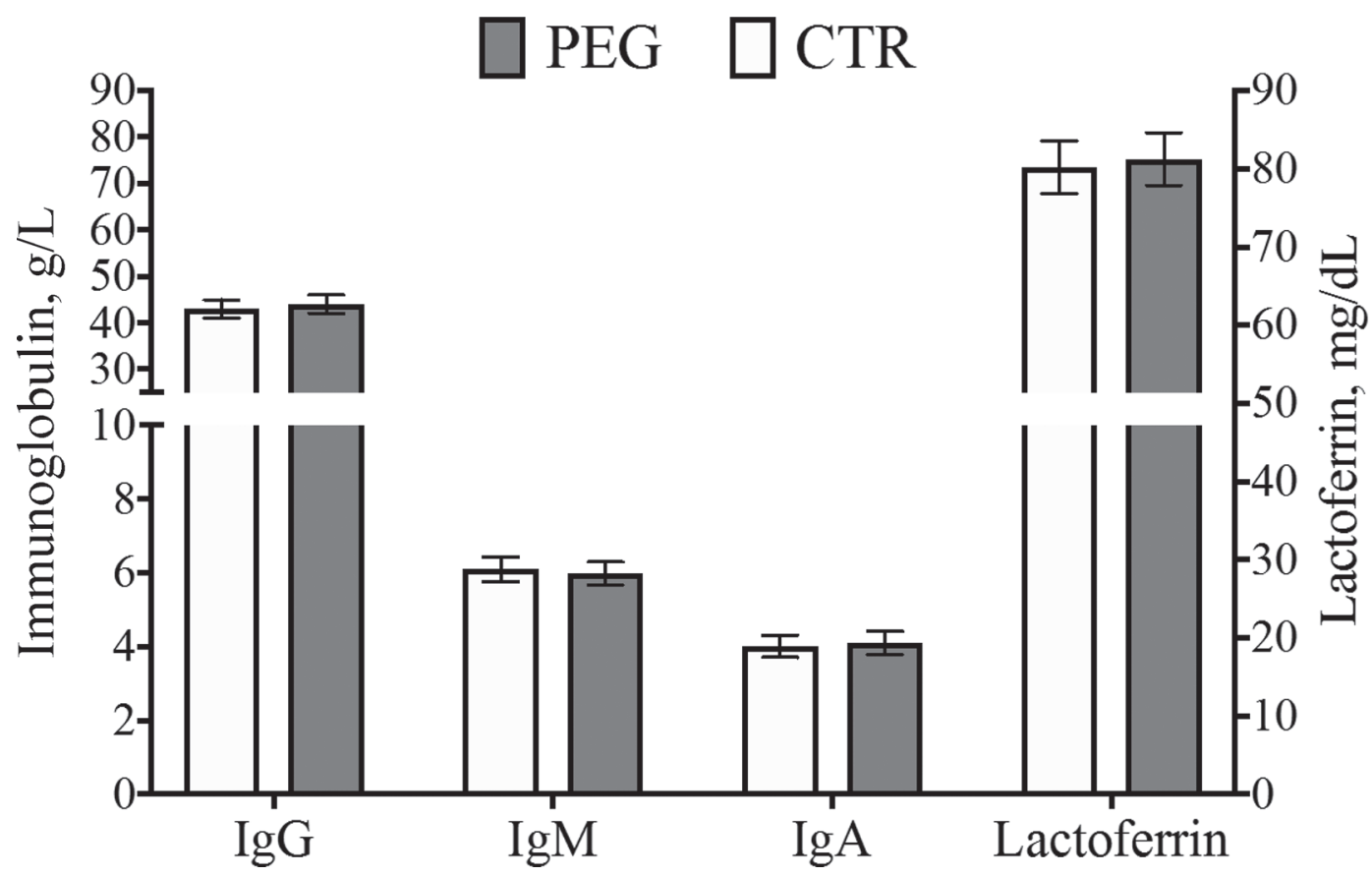

Figure 7. Colostrum concentrations of IgG, IgM, and IgA, and lactoferrin of cows treated with pegbovigrastim (PEG, n = 100) and controls $(\mathrm{CTR}, \mathrm{n}=100)$. Results are presented as LSM \pm SEM.

tion of PEG might trigger a more robust inflammatory response in sick animals and thus more animals exhibiting apparent clinical signs. This hypothesis needs to be further investigated.

In the study by Ruiz et al. (2017), cows that received PEG had a $5.8 \%$ higher chance of being inseminated within the first 100 DIM postpartum, whereas Canning et al. (2017) reported a 52\% reduction in failure to return to estrus by 80 DIM in cows treated with PEG relative to control cows. In our study, reproductive performance was not affected by PEG treatment. Although $\mathrm{P} / \mathrm{AI}$ at first service was not statistically increased $(P=0.11)$, we observed that cows treated with PEG had a 5.5-percentage-point numerical increase in $\mathrm{P} / \mathrm{AI}$ at first service when compared with CTR cows $(\mathrm{PEG}=34.3, \mathrm{CTR}=28.8 \%)$. The lack of differences in $\mathrm{P} / \mathrm{AI}$ at first service should be interpreted with caution because our study was not powered to detect significant differences in $\mathrm{P} / \mathrm{AI}$ between treatment groups with the observed percentage differences. More studies with a larger sample size are needed to evaluate whether differences in $\mathrm{P} / \mathrm{AI}$ at first service should be expected with the use of PEG.

As an adaptive response to negative energy balance, postpartum dairy cows exhibit an elevation of plasma NEFA and BHB, which are metabolic changes necessary to support milk synthesis and body energy demands (Bauman and Currie, 1980; Baumgard et al., 2017).
However, excessive production of BHB during early lactation has been associated with increased risk of postpartum disorders, decreased milk production, and poor reproductive performance (Duffield et al., 2009; McArt et al., 2012, 2013). In the present study, we observed that primiparous cows treated with PEG tended to have lower odds of developing HYK compared with nontreated primiparous cows. These results should be interpreted with caution, as the incidence of HYK was calculated from a small number of cows (PEG, $\mathrm{n}=37$; CTR, $\mathrm{n}=39$ ). Further studies with a larger sample size are needed to evaluate whether differences in HYK during the early postpartum should be expected with the use of PEG and to elucidate the mechanism by which PEG lowers the incidence of HYK. Additionally, we found no association between NEFA and PEG administration, which is in agreement with previous work (McDougall et al., 2017).

Canning et al. (2017) reported similar milk composition between PEG-treated and control cows. Our results on milk composition confirm that PEG does not affect protein and fat synthesis. We observed that primiparous animals treated with PEG produced more milk when compared with CTR primiparous cows; however, ECM yield was not affect by PEG. Assuming that DMI was similar between treatment groups, the underlying mechanism that primiparous cows treated with PEG faced to produce more milk warrants further 
investigation. Moreover, our finding that administration of PEG $7 \mathrm{~d}$ before the anticipated date of calving does not affect calf viability is also in agreement with the study by Canning et al. (2017).

We observed that animals treated with PEG had a higher incidence of DA relative to controls. The development of DA has been linked to elevated serum NEFA and $\mathrm{BHB}$ concentrations during the first week after parturition (LeBlanc et al., 2005; Duffield et al., 2009; Chapinal et al., 2011). In the present study, however, plasma NEFA and BHB were not affected by PEG treatment. Indeed, treated primiparous cows tended to have a lower incidence of HYK. Moreover, decreased plasma Ca levels at calving have been associated with a higher risk of developing DA (Massey et al., 1993; Neves et al., 2018). We observed that the proportion of multiparous cows (lactation $\geq 3$ ) with $\mathrm{SCH}$ did not differ between the PEG-treated and control groups. Thus, we cannot explain the detected effect of PEG treatment on DA.

Interestingly, PEG treatment increases the incidence of lameness during the first $30 \mathrm{DIM}$, although by 60 DIM we found no significant difference. The differences in the first 30 DIM were seen in multiparous animals with no observed lesion on examination. Milk yield in cows that received PEG and were lame in the first 30 DIM tended to be greater than the lame cows in the CTR group. The observation of lameness in multiparous animals without any observed foot lesions could be associated with side effects in humans. Bone or musculoskeletal pain is the most common adverse effect caused by G-CSF treatment in humans; however, the human dose is significantly higher than in dairy cows (Renwick et al., 2009; Kirshner et al., 2012; Lambertini et al., 2014). The human pegylated molecule, pegfilgrastim, is dosed at $6 \mathrm{mg}$, which would deliver $100 \mu \mathrm{g} /$ $\mathrm{kg}$ in a $60-\mathrm{kg}$ human in contrast to a dose of 20 to 30 $\mu \mathrm{g} / \mathrm{kg}$ administered to dairy cows per label. Additionally, in safety studies investigating administration of the product at $1 \times, 2 \times$, and $3 \times$, no adverse events associated with the musculoskeletal system were reported (Hassfurther et al., 2015; FDA, 2016; Canning et al., 2017). Although the exact mechanism of bone pain following G-CSF administration is not fully understood, the following pathophysiological processes have been proposed: (1) quantitative and qualitative expansion of the bone marrow, (2) activation of receptors located in afferent nerve fibers, (3) recruitment and stimulation of inflammatory cells, and (4) osteoclast activation causing bone resorption (Renwick et al., 2009). More studies are needed to assess the effect of PEG on lameness and to elucidate the pathophysiological processes involved in this effect.
Although our study evaluated the effect of PEG administration in a randomized clinical trial with 840 cows, it was limited to a single dairy farm. Therefore, the external generalization of the results must be made cautiously.

\section{CONCLUSIONS}

Treatment with PEG did not affect the incidence of mastitis, metritis, puerperal metritis, or clinical endometritis, but it increased the incidence of lameness, $\mathrm{DA}$, and combined clinical diseases during the first 30 d postpartum. Administration of PEG increased milk yield in primiparous cows, but did not affect ECM, FCM, and milk composition. Additionally, PEG treatment did not alter reproductive performance. As expected, PEG administration induced postpartum neutrophilia, which also resulted in a higher recruitment of neutrophils to the mucosa of the reproductive tract of cows affected with metritis-PM. These changes in the leukocyte population, induced by PEG administration, were not accompanied by improvements in the health and reproductive performance of treated animals. In fact, the combined disease morbidity was increased for cows treated with PEG.

\section{ACKNOWLEDGMENTS}

This study was funded by Elanco Animal Health, Greenfield, Indiana.

\section{REFERENCES}

Bauman, D. E., and W. B. Currie. 1980. Partitioning of nutrients during pregnancy and lactation: a review of mechanisms involving homeostasis and homeorhesis. J. Dairy Sci. 63:1514-1529.

Baumgard, L. H., R. J. Collier, and D. E. Bauman. 2017. A 100-Year Review: Regulation of nutrient partitioning to support lactation. J. Dairy Sci. 100:10353-10366.

Bicalho, M. L., F. S. Lima, E. K. Ganda, C. Foditsch, E. B. Meira Jr., V. S. Machado, A. G. Teixeira, G. Oikonomou, R. O. Gilbert, and R. C. Bicalho. 2014. Effect of trace mineral supplementation on selected minerals, energy metabolites, oxidative stress, and immune parameters and its association with uterine diseases in dairy cattle. J. Dairy Sci. 97:4281-4295.

Cai, T. Q., P. G. Weston, L. A. Lund, B. Brodie, D. J. Mckenna, and W. C. Wagner. 1994. Association between neutrophil functions and periparturient disorders in cows. Am. J. Vet. Res. 55:934-943.

Canning, P., R. Hassfurther, T. TerHune, K. Rogers, S. Abbott, and D. Kolb. 2017. Efficacy and clinical safety of pegbovigrastim for preventing naturally occurring clinical mastitis in periparturient primiparous and multiparous cows on US commercial dairies. J. Dairy Sci. 100:6504-6515.

Cha, E., D. Bar, J. A. Hertl, L. W. Tauer, G. Bennett, R. N. Gonzalez, Y. H. Schukken, F. L. Welcome, and Y. T. Grohn. 2011. The cost and management of different types of clinical mastitis in dairy cows estimated by dynamic programming. J. Dairy Sci. 94:4476-4487.

Chapinal, N., M. Carson, T. F. Duffield, M. Capel, S. Godden, M. Overton, J. E. Santos, and S. J. LeBlanc. 2011. The association 
of serum metabolites with clinical disease during the transition period. J. Dairy Sci. 94:4897-4903.

Cooper, K. L., J. Madan, S. Whyte, M. D. Stevenson, and R. L. Akehurst. 2011. Granulocyte colony-stimulating factors for febrile neutropenia prophylaxis following chemotherapy: Systematic review and meta-analysis. BMC Cancer 11:404.

Dubuc, J., T. F. Duffield, K. E. Leslie, J. S. Walton, and S. J. LeBlanc. 2010. Risk factors for postpartum uterine diseases in dairy cows. J. Dairy Sci. 93:5764-5771.

Dubuc, J., T. F. Duffield, K. E. Leslie, J. S. Walton, and S. J. Leblanc. 2011. Effects of postpartum uterine diseases on milk production and culling in dairy cows. J. Dairy Sci. 94:1339-1346.

Duffield, T. F., K. D. Lissemore, B. W. McBride, and K. E. Leslie. 2009. Impact of hyperketonemia in early lactation dairy cows on health and production. J. Dairy Sci. 92:571-580.

Edmonson, A. J., I. J. Lean, L. D. Weaver, T. Farver, and G. Webster. 1989. A body condition scoring chart for Holstein dairy-cows. J. Dairy Sci. 72:68-78.

Ezzat Alnakip, M., M. Quintela-Baluja, K. Bohme, I. Fernandez-No, S. Caamano-Antelo, P. Calo-Mata, and J. Barros-Velazquez. 2014 The immunology of mammary gland of dairy ruminants between healthy and inflammatory conditions. J. Vet. Med. 2014:659801.

FDA. 2016. Imrestor, pegbovigrastrim injection. Accessed May 2 2016. https://animaldrugsatfda.fda.gov/adafda/app/search/ public/document/downloadFoi/910.

Fetrow, J., S. Stewart, S. Eicker, R. Farnsworth, and R. Bey. 2000. Mastitis: An economic consideration. Pages 3-47 in National Mastitis Council Annual Meeting Proceedings, Atlanta, GA. Natl. Mastitis Counc. Inc., Madison, WI.

Fricke, P. M., D. Z. Caraviello, K. A. Weigel, and M. L. Welle. 2003. Fertility of dairy cows after resynchronization of ovulation at three intervals following first timed insemination. J. Dairy Sci. 86:39413950.

Ganda, E. K., R. S. Bisinotto, D. H. Decter, and R. C. Bicalho. 2016. Evaluation of an on-farm culture system (Accumast) for fast identification of milk pathogens associated with clinical mastitis in dairy cows. PLoS One 11:e0155314.

George, J. W., J. Snipes, and V. M. Lane. 2010. Comparison of bovine hematology reference intervals from 1957 to 2006. Vet. Clin. Pathol. 39:138-148.

Gilbert, R. O., and N. R. Santos. 2016. Dynamics of postpartum endometrial cytology and bacteriology and their relationship to fertility in dairy cows. Theriogenology 85:1367-1374.

Goff, J. P., and R. L. Horst. 1997. Physiological changes at parturition and their relationship to metabolic disorders. J. Dairy Sci. 80:1260-1268.

Goff, J. P., R. L. Horst, P. W. Jardon, C. Borelli, and J. Wedam. 1996. Field trials of an oral calcium propionate paste as an aid to prevent milk fever in periparturient dairy cows. J. Dairy Sci. 79:378-383.

Gröhn, Y. T., D. J. Wilson, R. N. Gonzalez, J. A. Hertl, H. Schulte, G. Bennett, and Y. H. Schukken. 2004. Effect of pathogen-specific clinical mastitis on milk yield in dairy cows. J. Dairy Sci. 87:3358-3374.

Gunnink, J. W. 1984a. Pre-partum leucocytic activity and retained placenta. Vet. Q. 6:52-54.

Gunnink, J. W. 1984b. Retained placenta and leucocytic activity. Vet. Q. 6:49-51.

Hammon, D. S., I. M. Evjen, T. R. Dhiman, J. P. Goff, and J. L. Walters. 2006. Neutrophil function and energy status in Holstein cows with uterine health disorders. Vet. Immunol. Immunopathol. 113:21-29.

Hassfurther, R. L., T. N. TerHune, and P. C. Canning. 2015. Efficacy of polyethylene glycol-conjugated bovine granulocyte colonystimulating factor for reducing the incidence of naturally occurring clinical mastitis in periparturient dairy cows and heifers. Am. J. Vet. Res. 76:231-238.

Hussain, A. M. 1989. Bovine uterine defense mechanisms: a review. Zentralbl. Veterinarmed. B. 36:641-651.
Kehrli, M. E. Jr., B. J. Nonnecke, and J. A. Roth. 1989. Alterations in bovine neutrophil function during the periparturient period. Am. J. Vet. Res. 50:207-214.

Kelton, D. F., K. D. Lissemore, and R. E. Martin. 1998. Recommendations for recording and calculating the incidence of selected clinical diseases of dairy cattle. J. Dairy Sci. 81:2502-2509.

Kimura, K., J. P. Goff, P. Canning, C. Wang, and J. A. Roth. 2014 Effect of recombinant bovine granulocyte colony-stimulating factor covalently bound to polyethylene glycol injection on neutrophil number and function in periparturient dairy cows. J. Dairy Sci. 97:4842-4851.

Kimura, K., J. P. Goff, and M. E. Kehrli Jr.. 1999. Effects of the presence of the mammary gland on expression of neutrophil adhesion molecules and myeloperoxidase activity in periparturient dairy cows. J. Dairy Sci. 82:2385-2392.

Kimura, K., J. P. Goff, M. E. Kehrli, and T. A. Reinhardt. 2002. Decreased neutrophil function as a cause of retained placenta in dairy cattle. J. Dairy Sci. 85:544-550.

Kirshner, J. J., C. E. Heckler, M. C. Janelsins, S. R. Dakhil, J. O. Hopkins, C. Coles, and G. R. Morrow. 2012. Prevention of pegfilgrastim-induced bone pain: a phase III double-blind placebocontrolled randomized clinical trial of the university of rochester cancer center clinical community oncology program research base. J. Clin. Oncol. 30:1974-1979.

Lambertini, M., L. Del Mastro, A. Bellodi, and P. Pronzato. 2014. The five "Ws" for bone pain due to the administration of granulocytecolony stimulating factors (G-CSFs). Crit. Rev. Oncol. Hematol. $89: 112-128$

Landin, H., M. J. Mork, M. Larsson, and K. P. Waller. 2015. Vaccination against Staphylococcus aureus mastitis in two Swedish dairy herds. Acta Vet. Scand. 57:81.

LeBlanc, S. J., K. E. Leslie, and T. F. Duffield. 2005. Metabolic predictors of displaced abomasum in dairy cattle. J. Dairy Sci 88:159-170.

Massey, C. D., C. Wang, G. A. Donovan, and D. K. Beede. 1993. Hypocalcemia at parturition as a risk factor for left displacement of the abomasum in dairy cows. J. Am. Vet. Med. Assoc. 203:852-853.

McArt, J. A., D. V. Nydam, and G. R. Oetzel. 2012. Epidemiology of subclinical ketosis in early lactation dairy cattle. J. Dairy Sci 95:5056-5066.

McArt, J. A., D. V. Nydam, G. R. Oetzel, T. R. Overton, and P. A. Ospina. 2013. Elevated non-esterified fatty acids and betahydroxybutyrate and their association with transition dairy cow performance. Vet. J. 198:560-570.

McDougall, S., S. J. LeBlanc, and A. Heiser. 2017. Effect of prepartum energy balance on neutrophil function following pegbovigrastim treatment in periparturient cows. J. Dairy Sci. 100:7478-7492.

Moreira, F., C. Orlandi, C. A. Risco, R. Mattos, F. Lopes, and W. W. Thatcher. 2001. Effects of presynchronization and bovine somatotropin on pregnancy rates to a timed artificial insemination protocol in lactating dairy cows. J. Dairy Sci. 84:1646-1659.

Nagata, S. 1989. Gene structure and function of granulocyte colonystimulating factor. BioEssays 10:113-117.

Neves, R. C., B. M. Leno, M. D. Curler, M. J. Thomas, T. R. Overton, and J. A. A. McArt. 2018. Association of immediate postpartum plasma calcium concentration with early-lactation clinical diseases, culling, reproduction, and milk production in Holstein cows. J. Dairy Sci. 101:547-555.

Oliver, S. P., and S. E. Murinda. 2012. Antimicrobial resistance of mastitis pathogens. Vet. Clin. North Am. Food Anim. Pract. $28: 165-185$.

Paape, M., J. Mehrzad, X. Zhao, J. Detilleux, and C. Burvenich. 2002. Defense of the bovine mammary gland by polymorphonuclear neutrophil leukocytes. J. Mammary Gland Biol. Neoplasia 7:109-121.

Pol, M., and P. L. Ruegg. 2007. Treatment practices and quantification of antimicrobial drug usage in conventional and organic dairy farms in Wisconsin. J. Dairy Sci. 90:249-261.

Pollmächer, T., C. Korth, W. Schreiber, D. Hermann, and J. Mullington. 1996. Effects of repeated administration of granulocyte 
colony-stimulating factor (G-CSF) on neutrophil counts, plasma cytokine, and cytokine receptor levels. Cytokine 8:799-803.

Pursley, J. R., M. O. Mee, and M. C. Wiltbank. 1995. Synchronization of ovulation in dairy cows using PGF2alpha and GnRH. Theriogenology 44:915-923

Renwick, W., R. Pettengell, and M. Green. 2009. Use of filgrastim and pegfilgrastim to support delivery of chemotherapy: Twenty years of clinical experience. BioDrugs 23:175-186.

Reyes, E., I. Garcia-Castro, F. Esquivel, J. Hornedo, H. Cortes-Funes, J. Solovera, and M. Alvarez-Mon. 1999. Granulocyte colony-stimulating factor (G-CSF) transiently suppresses mitogen-stimulated T-cell proliferative response. Br. J. Cancer 80:229-235.

Ribeiro, E. S., F. S. Lima, L. F. Greco, R. S. Bisinotto, A. P. Monteiro, M. Favoreto, H. Ayres, R. S. Marsola, N. Martinez, W. W. Thatcher, and J. E. Santos. 2013. Prevalence of periparturient diseases and effects on fertility of seasonally calving grazing dairy cows supplemented with concentrates. J. Dairy Sci. 96:5682-5697.

Rinaldi, M., P. Moroni, M. J. Paape, and D. D. Bannerman. 2008. Differential alterations in the ability of bovine neutrophils to generate extracellular and intracellular reactive oxygen species during the periparturient period. Vet. J. 178:208-213.

Ruegg, P. L., and T. J. Tabone. 2000. The relationship between antibiotic residue violations and somatic cell counts in Wisconsin dairy herds. J. Dairy Sci. 83:2805-2809.
Ruiz, R., L. O. Tedeschi, and A. Sepulveda. 2017. Investigation of the effect of pegbovigrastim on some periparturient immune disorders and performance in Mexican dairy herds. J. Dairy Sci. 100:33053317.

Schreiner, D. A., and P. L. Ruegg. 2003. Relationship between udder and leg hygiene scores and subclinical mastitis. J. Dairy Sci. 86:3460-3465

Seegers, H., C. Fourichon, and F. Beaudeau. 2003. Production effects related to mastitis and mastitis economics in dairy cattle herds. Vet. Res. 34:475-491.

Sheldon. I. M., G. S. Lewis, S. LeBlanc, and R. O. Gilbert. 2006. Defining postpartum uterine disease in cattle. Theriogenology 65:1516-1530.

Waller, K. P. 2000. Mammary gland immunology around parturition. Influence of stress, nutrition and genetics. Adv. Exp. Med. Biol. 480:231-245.

Williamson, D. H., and J. Mellanby. 1974. D-(-)-3-hydroxybutyrate. Pages 1836-1839 in Methods of Enzymatic Analysis. H. U. Bergmeyer, ed. Academic Press, New York, NY. 